\title{
On the bulk composition of the lower mantle: predictions and limitations from generalized inversion of radial seismic profiles
}

\author{
J. Matas, ${ }^{1,3}$ J. Bass, ${ }^{2}$ Y. Ricard, ${ }^{1}$ E. Mattern ${ }^{1}$ and M. S. T. Bukowinski ${ }^{3}$ \\ ${ }^{1}$ Laboratoire de Sciences de la Terre, CNRS UMR 5570, Ecole normale supérieure de Lyon, 69007 Lyon, France \\ ${ }^{2}$ Department of Geology, University of Illinois at Urbana-Champaign, Urbana, IL 61801, USA \\ ${ }^{3}$ Department of Earth and Planetary Science, University of California, Berkeley, CA 94720, USA
}

Accepted 2007 March 27. Received 2007 March 27; in original form 2006 February 15

\begin{abstract}
SUMMAR Y
We examine the problem of obtaining the thermal structure and bulk chemical composition of the lower mantle from its seismologically determined velocity and density profiles, and the most recent results on the elastic properties of the relevant phases (including, of particular importance, shear moduli). A novel aspect of this paper is the application of an iterative technique solving generalized non-linear inverse problem, which allows us to simultaneously consider a complex chemical system (the $\mathrm{MgO}-\mathrm{FeO}-\mathrm{SiO}_{2}-\mathrm{Al}_{2} \mathrm{O}_{3}-\mathrm{CaO}$ system, which includes all major components in the lower mantle), and to rigorously evaluate the full covariance and resolution matrices. The effects of experimental uncertainties in the shear moduli are carefully accounted for. We show that although the a posteriori uncertainties in the results for lower-mantle compositions are relatively large, the averaged lower-mantle $\mathrm{Mg} / \mathrm{Si}$ ratio should be lower than 1.3 in order to satisfactorily fit the 1-D seismic profiles. Two distinct families of best-fitting models are determined. The first is based upon a value for the pressure derivative of the perovskite shear modulus that is representative of various existing experimental measurements $\left(\mu_{0}^{\prime}=1.8\right)$. Under this assumption, it is not possible to match the lower mantle seismic properties with an adiabatic geotherm and uniform chemical composition. Instead, this family of solutions is characterized by a geotherm with large temperature gradients $(d T / d z$ increases from 0.5 to $0.9 \mathrm{~K} \mathrm{~km}^{-1}$ between 800 and $2700 \mathrm{~km}$ and the temperature reaches $3400 \mathrm{~K}$ at the depth of $2700 \mathrm{~km}$ ), and a depth dependent bulk composition with an $\mathrm{Mg} / \mathrm{Si}$ ratio decreasing from $1.18 \pm$ 0.14 to $1.03 \pm 0.16$ between 800 and $2700 \mathrm{~km}$. The second family of solutions is obtained when we attempt to fit the lower mantle with a simpler compositional and thermal structure. This can only be done when the pressure derivative of the shear modulus for perovskite is close to the most recent values obtained by Brillouin spectroscopy, that is, with a $\mu_{0}^{\prime}$ close to 1.6 instead of 1.8. The resulting temperature gradient is $0.25 \mathrm{~K} \mathrm{~km}^{-1}$ in the upper part of the lower mantle and $0.5 \mathrm{~K} \mathrm{~km}^{-1}$ below $1700 \mathrm{~km}$ depth; the geotherm reaches $2800 \mathrm{~K}$ at a depth of $2700 \mathrm{~km}$. Corresponding $\mathrm{Mg} / \mathrm{Si}$ ratio remains rather constant and close to 1.16 throughout the lower mantle. We show that the temperature gradient is strongly correlated with the pressure derivative $\mu_{0}^{\prime}$ of the shear modulus of perovskite: lower values of $\mu_{0}^{\prime}$ imply lower thermal gradients. We also discuss the importance of the Bullen parameter as an additional constraint. In order to refine conclusions on the lower-mantle structure, additional independent observables, such as accurate observations on electrical conductivity and 1-D $Q$ profiles, are necessary.
\end{abstract}

Key words: density, inverse problem, mantle, mineralogy, seismic velocities.

\section{INTRODUCTION}

The structure and composition of the lower mantle have been under intense debate for several decades. Various fundamental questions remain without adequate answers. One of them is undoubtedly the interpretation of the global laterally averaged chemical composition of the lower mantle. The discrepancy in chemistry between chon- drites (presumably the primordial building material for the Earth), and peridotitic rocks (that sample the shallow mantle to a depth of about $200 \mathrm{~km}$ ), has not been satisfactorily explained. There exist different classes of chondrites, and chemical compositions within each class, as given by different compilations, may vary by up to 10 per cent (e.g. Jarosewich 1990; Newsom 1995). The carbonaceous chondrites are often used to construct compositional models 
(e.g. Hart \& Zindler 1986; McDonough \& Sun 1995; Lyubetskaya $\&$ Korenaga 2007). However, there is no clear consensus on which class of chondrites (if any of those known) represents the dominant primordial material involved in the Earth's accretionary processes (see e.g. Javoy 1995; Williams \& Knittle 2005). Additional difficulties arise from assumptions on the refractory nature of different elements. For instance, Hart \& Zindler (1986) developed two distinct compositional models of the primitive mantle, both based on $\mathrm{C} 1$ chondrites and available upper-mantle petrological constraints but adopting different refractory behaviour of $\mathrm{Mg}$ and Si. First, assuming $\mathrm{Si}$ and $\mathrm{Mg}$ as purely refractory elements, they obtained the ' $\mathrm{C} 1$ model' with an $\mathrm{Mg} / \mathrm{Si}$ ratio of 1.074 which, therefore, required different upper- and lower-mantle compositions. Second, allowing a slight deficiency of $\mathrm{Mg}$ and $\mathrm{Si}$ in the Earth with respect to $\mathrm{Ca}$ and $\mathrm{Al}$ in chondrites, they derived the 'LOSIMAG $\mathrm{C} 1$ model' with an $\mathrm{Mg} / \mathrm{Si}$ ratio of 1.225 . Consequently, there was no need for compositionally distinct upper and lower mantles. Other models based on chemical analyses of carbonaceous chondrites and uppermantle samples give rather similar values of $\mathrm{Mg} / \mathrm{Si}$ ratio for the primitive mantle, for example, 1.265 by Morgan \& Anders (1980) 1.221 by Allègre et al. (1995), 1.252 by McDonough \& Sun (1995). Lyubetskaya \& Korenaga (2007) performed a detailed statistical analysis of the available geochemical constraints and obtained an $\mathrm{Mg} / \mathrm{Si}$ ratio of $1.282 \pm 0.086$.

In order to reconcile the observed composition of mid-oceanic basaltic magmas and residual lithosphere formed upon partial melting, so-called pyrolitic models (mixtures of olivine and pyroxene) were introduced (e.g. Green \& Ringwood 1963; Ringwood \& Kesson 1977; Jackson \& Ridgen 1998). The resulting $\mathrm{Mg} / \mathrm{Si}$ ratio in these models is always close to 1.27 . Several alternatives to the pyrolitic models have also been proposed. Anderson (1983) constructed a compositional model based on mass balance of various mantle components. He deduced a lower-mantle $\mathrm{Mg} / \mathrm{Si}$ ratio of 1.095. Anderson \& Bass (1986) introduced a piclogitic (instead of pyrolitic) model for the transition zone together with a silica rich lower mantle where $\mathrm{Mg} / \mathrm{Si}=1.031$. Detailed discussion of other compositional models can be found in the literature (e.g. Anderson 1989) and are recently reviewed by Lyubetskaya \& Korenaga (2007). Since the style of mantle convection and mixing efficiency is not precisely known, one can argue that available sublithospheric peridotitic samples might not represent the chemical composition of the whole mantle. Therefore, the question of the lower-mantle composition remains open. Aside from the uncertain radial structure, recent seismological observations (see e.g. Robertson \& Woodhouse 1996; Su \& Dziewonski 1997; van der Hilst \& Karason 1999; Masters et al. 2000; Kennett et al. 2001; Saltzer et al. 2001; Garnero 2004; Kennett \& Gorbatov 2004) suggest the existence of significant lateral chemical heterogeneities in the lower mantle, and especially in its lower-most part.

A large number of studies have examined the mineralogical interpretation of seismological profiles of density, bulk modulus, and, less frequently, shear wave velocities and shear moduli. In principle, there are two distinct classes of observables - radial averages or fully 3-D models - and, consequently, two different types of interpretations. First, 1-D radial profiles that can be modelled using different geotherms and various depth-dependent models of bulk mantle chemistry provide information on laterally averaged mantle properties. Second, lateral variations in temperature and chemistry can be constrained by fitting the lateral anomalies of density and elastic properties determined by seismic tomography, that is, by 3 -D seismic models. The second type of inversion has been reviewed by Trampert \& van der Hilst (2005) and will not be discussed here.
Studies of 1-D profiles differ among themselves due to the use of: (1) different observables, most often either the seismic velocities $V_{p}$ and $V_{s}$ (e.g. Deschamps \& Trampert 2004; Cammarano et al. 2005), or density $\rho$ and bulk sound velocity $V_{\phi}$ (e.g. Jackson 1998 ; Mattern et al. 2005); (2) different data sets of compressional and shear properties for candidate lower-mantle phases and (3) different equations of state (EoS) for extrapolating the elastic properties under lower-mantle $P-T$ conditions. They also may assume different a priori mantle chemistries (a simplified three component $\mathrm{MgO}-$ $\mathrm{FeO}-\mathrm{SiO}_{2}$ system versus a more realistic compositions containing additional major elements, such as aluminum or calcium), and different geotherms (adjustable or fixed adiabatic temperature profiles). $\mathrm{Up}$ to this point, there has been no study of mantle temperature and composition considering the $\mathrm{MgO}-\mathrm{FeO}-\mathrm{CaO}-\mathrm{Al}_{2} \mathrm{O}_{3}-\mathrm{SiO}_{2}$ system using rigorous inversion techniques. The effect of simultaneously including the important major components, such as $\mathrm{Al}_{2} \mathrm{O}_{3}$ and $\mathrm{CaO}$, on inferred mantle compositions and temperature has not been sufficiently discussed.

Lower-mantle temperature and composition have most often been studied using density and the seismic parameter (or bulk sound velocity) as observables (see e.g. Jackson 1998; Mattern et al. 2005, and the references therein). Using a Bayesian approach to solve the inverse problem, Mattern et al. (2005) emphasized the existence of significant trade-offs between thermal structure and bulk composition. These trade-offs prevent a clear distinction between different competing models: both pyrolitic and chondritic (i.e. silica-rich) compositional models have been found to be in agreement with seismological observations. In other words, using only the bulk sound velocity and density as constraints does not yield a unique solution for mantle composition and temperature.

In an attempt to resolve these ambiguities, Deschamps \& Trampert (2004) made use of the experimental and theoretical determinations of the shear properties of lower-mantle phases in the $\mathrm{MgO}-\mathrm{FeO}-\mathrm{SiO}_{2}$ system. Their study emphasized the fact that using measurements of shear properties significantly decreases the resulting uncertainties. They concluded that the mantle geotherm is not adiabatic and showed that the proportion of perovskite may change with depth. Two distinct solutions were suggested, depending on the elastic properties used in the inversion: the first with a nearly adiabatic gradient and a decreasing proportion of perovskite with depth, and a second solution with a superadiabatic gradient and a nearly constant composition. They also pointed out that using the values of elastic moduli from laboratory measurements yields different conclusions than those obtained by using elastic moduli from theoretical computations. Deschamps \& Trampert (2004) also discussed the importance and implications of different values for shear modulus $\mu_{0}$ (and its pressure derivative, $\mu_{0}^{\prime}$ ), subject to their assumptions about mantle composition. They argued that a better fit to the seismic data is obtained with a lower value of $\mu_{0}^{\prime}$ for perovskite ( $\mu_{0}^{\prime}=1.5$ ) obtained by first principle calculations (Kiefer et al. 2002) than the observed value of 1.8 by Sinelnikov et al. (1998). Jackson (1998) also pointed out a possible discrepancy between the pressure derivative of shear modulus obtained from experiments and a value of $\mu_{0}^{\prime}$ inferred from fitting radial seismological profiles. He inferred a value of $\mu_{0}^{\prime}=1.55$ using Stacey's empirical law $\left(\mu=A P+B K_{S}\right)$, and assuming a mantle adiabat. In contrast to the results of Jackson (1998) and Deschamps \& Trampert (2004), Li \& Zhang (2005) concluded that lower-mantle velocities could be matched by a pyrolite mineralogy along an adiabatic gradient with a relatively large value of $\mu_{0}^{\prime}=2.0$ for magnesium silicate perovskite. The stark differences in conclusions among these authors warrants a re-examination of lower-mantle mineralogy 
and thermal structure, and its sensitivity to the thermoelastic input properties.

New information on the shear moduli of silicate perovskite have recently emerged from laboratory experiments. However, significant differences remain in the measured values of the pressure derivative of the shear modulus, $\mu_{0}^{\prime}$. Using ultrasonic measurements Li \& Zhang (2005) reported a value of 2.0(1) whereas Murakami et al. (2007) found a $\mu_{0}^{\prime}$ of 1.56(4) by using Brillouin spectroscopy. Murakami et al. (2007) concluded that when the low value of $\mu_{0}^{\prime}$ is adopted, the averaged radial profile of seismic velocities in the lower mantle is best fitted with a nearly adiabatic geotherm and a composition containing 85-90 per cent of perovskite, that is, they deduced a lower-mantle $\mathrm{Mg} / \mathrm{Si}$ ratio of 1.1. However, since they did not perform a formal inversion, they did not evaluate the uncertainties associated with their best-fitting model and did not explore possible correlations between composition and temperature. Similarly to previous studies, the effects of seismic attenuation have not been taken into account. Cammarano et al. (2005), used seismic traveltimes (instead of velocities) as observables, and studied their compatibility with pyrolite bulk chemistry and different geotherms. They allowed the mineral properties to change in order to identify possible sets of elastic parameters that would be compatible with an adiabat and the observed traveltimes. They concluded that a pyrolitic mantle having an adiabatic geotherm is consistent with the seismic observation only for a very restricted set of elastic properties.

No clear consensus on the actual geotherm and composition of the lower mantle has emerged from the previous studies. The presence of a discontinuity in chemical composition across the $660-\mathrm{km}$ interface (in addition to phase changes), or deeper in the lower mantle is still under debate. A large number of geodynamic studies favour only a phase transition at $660 \mathrm{~km}$ in a homogeneous mantle (e.g. Richards \& Hager 1984; Ricard et al. 1984; see Ricard \& Coltice 2004 for a review), whereas some geochemical studies tend to support a chemical discontinuity at $660-\mathrm{km}$ depth (see e.g. Hofmann 1997). Regardless of the nature of the 660-km interface, other chemical discontinuities may exist in the lower mantle (e.g. Anderson 2005). A large number of recent interpretations of deep mantle lateral heterogeneities suggest an increase of iron and silicon content in the deep mantle (see e.g. Trampert \& van der Hilst 2005). Some studies based on geochemical analyses of mid-oceanic ridge basalts and ocean islands basalts, combined with geodynamic considerations, suggest a lower mantle with deep long-lived chemically heterogeneous domains that would correspond to either hypothetical primordial material having a chondrite-like composition, or the presence of ancient segregated oceanic crust (see e.g. Christensen \& Hofmann 1994; Coltice \& Ricard 1999; Davaille 1999; Kellogg et al. 1999; Albarède \& van der Hilst 2002; Samuel et al. 2005; Tackley et al. 2005; Williams \& Knittle 2005). The spatial distribution and shape of possible chemical heterogeneities are however not well resolved (e.g. Albarède 2005). A weakness in virtually all previous studies is that the role of minor elements (such as aluminum, calcium and water) remains unknown. This is primarily due to the difficulty of performing the laboratory measurements needed to identify the effect of chemical variations on the elastic properties of the major lower mantle phases. Recent laboratory experiments by Murakami et al. (2004), Badro et al. (2003) and Badro et al. (2004) indicate that other phase transitions may occur in the lower mantle. However, the characteristics of these transitions (Clapeyron slope, change in density and elastic properties), as well as their exact location in the real mantle are still under debate (e.g. Li et al. 2004; Speziale et al. 2005; Hofmeister 2006).
In this paper, we examine lower-mantle temperature and composition profiles considering all the likely major elements, that is, the $\mathrm{MgO}-\mathrm{FeO}-\mathrm{CaO}-\mathrm{Al}_{2} \mathrm{O}_{3}-\mathrm{SiO}_{2}$ compositional space, and the radial profiles of density and seismic velocities given by ak135 model (Kennett et al. 1995). The problem of determining composition and temperature is an intrinsically underdetermined problem. In order to perform a more objective inversion, we apply a least-square criterion for solving the generalized non-linear inversion problem. We also aim to precisely evaluate uncertainties related to the best-fitting models and correlations between model parameters (temperature, composition and elastic properties of lower-mantle minerals). The approach has been discussed by Tarantola \& Valette (1982) and its details are described in Tarantola (1987). The rigorous mathematical treatment developed in the Bayesian approach attributes a statistical significance to the solution of the underdetermined problem by comparing a priori uncertainties to the obtained a posteriori uncertainties. The specification of an a priori covariance (variance and trade-offs) is, however, neither easy for the observations nor for the model parameters. The averaged radial density and seismic velocity profiles of the Earth is the result of a complex inversion for which the resulting covariance matrix is not known. The situation is even less clear for the thermoelastic parameters that we compiled from a large number of publications where the experimental data had already gone through often poorly documented fitting procedures. Similarly, most of the geochemical studies do not provide complete information on the covariance of their compositional parameters. In spite of these difficulties, our approach allows us to make fewer $a$ priori assumptions in assessing the lower-mantle structure in a more comprehensive way than previous studies.

\section{ELASTICITY DATA SET}

We describe the bulk chemistry of the lower mantle in terms of five oxide components $\left(\mathrm{MgO}, \mathrm{FeO}, \mathrm{CaO}, \mathrm{Al}_{2} \mathrm{O}_{3}\right.$ and $\left.\mathrm{SiO}_{2}\right)$. The chemical elements are distributed within three distinct mineralogical phases: magnesian silicate perovskite $(\mathrm{Mg}, \mathrm{Fe}, \mathrm{Al})(\mathrm{Si}, \mathrm{Al}) \mathrm{O}_{3}(\mathrm{Pv})$, magnesiowüstite $(\mathrm{Mg}, \mathrm{Fe}) \mathrm{O}(\mathrm{Mw})$ and calcium perovskite $\mathrm{CaSiO}_{3}(\mathrm{CaPv})$. These three major mineralogical phases are modelled with six different end-members: $\mathrm{MgSiO}_{3}-\mathrm{MgPv}, \mathrm{FeSiO}_{3}-\mathrm{FePv}, \mathrm{Al}_{2} \mathrm{O}_{3}-$ (Mg,Al)-Pv, $\mathrm{MgO}$ - Periclase, $\mathrm{FeO}-$ Wüstite and $\mathrm{CaSiO}_{3}-\mathrm{CaPv}$.

\subsection{Equation of state and thermal corrections of elastic properties}

In order to compute the effect of pressure on density and the bulk modulus, we use the third order Birch-Murnaghan equation of state (see Appendix A) and the elastic properties from Table 1. These values are taken from the recent review by Mattern et al. (2005). The effect of temperature on density and bulk modulus can be evaluated using several different methods. Two of them are described in Appendix B. Many experimental studies provide temperature derivatives of both volume and the bulk modulus (i.e. the coefficient of thermal expansion $\alpha$ and temperature derivative of bulk modulus $\left.\left(\partial K_{T} / \partial T\right)_{P}\right)$. They are obtained from a fit of high-pressure and high-temperature $P-V-T$ measurements. As pointed out by Jackson (1998) and Deschamps \& Trampert (2004), accurate values of the cross-derivatives of the bulk modulus, $\partial^{2} K_{T} / \partial P \partial T$, should be used when extrapolating the elastic moduli to lowermantle $P-T$ conditions. However, the uncertainties for the few existing experimental observations of these cross-derivatives are large. In 
Table 1. Room-pressure and room-temperature elastic properties of the six lower mantle end-membres used in this study.

\begin{tabular}{lccccc}
\hline & $\begin{array}{c}V_{0} \\
\left(\mathrm{~cm}^{3} \mathrm{~mol}^{-1}\right)\end{array}$ & $\begin{array}{c}K_{0, T} \\
(\mathrm{GPa})\end{array}$ & $K_{0}^{\prime}$ & $\begin{array}{c}\mu_{0} \\
(\mathrm{GPa})\end{array}$ & $\mu_{0}^{\prime}$ \\
\hline $\mathrm{MgPv}\left(\mathrm{MgSiO}_{3}\right)$ & $24.43^{1}$ & $250^{2}$ & $4.0^{3}$ & $175(5)^{4}$ & $1.8(4)^{5}$ \\
$\mathrm{FePv}\left(\mathrm{FeSiO}_{3}\right)$ & $25.34^{6}$ & $250^{a}$ & $4.0^{a}$ & $135^{7}$ & $1.3^{7}$ \\
$(\mathrm{Mg}, \mathrm{Al}) \mathrm{Pv}{ }^{b}$ & $24.58^{8}$ & $249^{8}$ & $4.0^{9}$ & $165^{8}$ & $1.8^{a}$ \\
Periclase $(\mathrm{MgO})$ & $11.25^{10}$ & $160.1^{11}$ & $3.83^{11}$ & $130(2)^{11}$ & $2.2(2)^{11}$ \\
Wüstite $(\mathrm{FeO})$ & $12.26^{6}$ & $160.1^{a}$ & $3.83^{a}$ & $46(2)^{12}$ & $0.6(2)^{12}$ \\
$\mathrm{CaPv}\left(\mathrm{CaSiO}_{3}\right)$ & $27.45^{13}$ & $236^{13}$ & $3.9^{13}$ & $165^{14}$ & $2.46^{14}$ \\
\hline
\end{tabular}

$V_{0}$ is the molar volume, $K_{0, T}$ isothermal bulk modulus, $K_{0, T}^{\prime}$ its pressure derivative; $\mu_{0}$ is shear modulus, and $\mu_{0}^{\prime}$ its pressure derivatives. Estimated uncertainties on shear moduli are specified in the parenthesis when available.

${ }^{a}$ same as the Mg-bearing end-member; ${ }^{b} \mathrm{Al}$-bearing $\mathrm{MgSiO}_{3}$ perovskite with 5 mol. per cent $\mathrm{Al}_{2} \mathrm{O}_{3}$.

Sources: ${ }^{1}$ e.g. Fiquet et al. (1998); ${ }^{2}$ after Sinogeikin et al. (2004); ${ }^{3}$ fixed to 4 as Fiquet et al. (1998); ${ }^{4}$ Sinogeikin et al. (2004), values 173(1) GPa and 172.9(1.5) GPa obtained by Li \& Zhang (2005) and Murakami et al. (2007), respectively, are within the stated uncertainties; ${ }^{5}$ Sinelnikov et al. (1998), uncertainty of 0.4 have been adopted in order to cover values $2.0 \pm$ 1 and $1.56 \pm 0.04$ measured by Li \& Zhang (2005) and Murakami et al. (2007), respectively; ${ }^{6}$ see Mattern et al. (2005); ${ }^{7}$ Kiefer et al. (2002); ${ }^{8}$ after Jackson et al. (2004); ${ }^{9}$ Daniel et al. (2004); ${ }^{10}$ Jackson \& Niesler (1982); ${ }^{11}$ after Sinogeikin \& Bass (2000); ${ }^{12}$ Jackson et al. (1990); ${ }^{13}$ Shim et al. (2000) and ${ }^{14}$ Karki \& Crain (1998)

Appendix C, we evaluate the effect of neglecting cross-derivatives and illustrate the possible bias to the predicted values of compressibility under lower mantle $P-T$ conditions. We therefore, favour the Mie-Grünesien EoS based on a Debye model of solids in order to keep our approach as thermodynamically consistent as possible (Stixrude \& Bukowinski 1990) and do not use the experimental finite-strain EoS in this study. The parameters required by the MieGrünesien EoS, the Debye temperature $\Theta_{D_{0}}$, Grüneisen parameter $\gamma_{0}$, and its volume derivative $q_{0}$ (see Appendix B), can be obtained from experiments (see e.g. Stixrude \& Lithgow-Bertelloni 2005) or from theoretical models (see e.g. Hama \& Suito 2001). The thermal properties predicted by this EoS are in agreement with the experimental values and the cross-derivatives that are not yet satisfactorily experimentally determined, are self-consistently accounted for.

In order to compute the shear properties as function of pressure at constant temperature we use the method of Davies (1974) (see Appendix A). It is analogous to the Birch-Murnaghan equation of state, requiring knowledge of a reference shear modulus $\mu_{0}$ and its pressure derivative, $\mu_{0}^{\prime}$, for each compound. The thermal corrections to the shear properties are more difficult to assess than those for the bulk modulus. Unless experimental and/or theoretical techniques provide the full elastic tensor as a function of temperature, existing estimates of thermal properties remain based on various approximations and systematics. In this study, we use the method developed by Hama \& Suito (1998), based on the Debye model that yields the shear modulus of an isotropic aggregate (see Appendix B).

\subsection{Shear moduli}

Due to experimental difficulties, there are relatively few measurements of shear moduli of mantle minerals. Three of the main measurement techniques: (1) Brillouin spectroscopy in diamond anvil cell (e.g. Sinogeikin \& Bass 2000; Sinogeikin et al. 2004), (2) ultrasonic measurements in a multi-anvil apparatus (e.g. Jackson \&
Niesler 1982; Sinelnikov et al. 1998) and (3) Ghz ultrasonics experiments (Jacobsen et al. 2002). The three methods provide measurements of both $V_{p}$ and $V_{s}$. The first method can be performed at lower-mantle pressures, while the latter two, although capable of high precision, are thus far limited to pressures below $20 \mathrm{GPa}$ (e.g. Li et al. 2005). Unfortunately, there are no measurements of shear properties at the simultaneous high-pressure and high-temperature conditions appropriate for the lower mantle.

An additional difficulty with shear measurements is associated with the fact that Brillouin spectroscopy is performed at frequencies of $>10 \mathrm{GHz}$, Ghz ultrasonics at a few $\mathrm{GHz}$, and the ultrasonic measurements at frequencies of the order of $\mathrm{MHz}$. An accurate extrapolation of laboratory measurements to seismically relevant frequencies of the order of $\mathrm{mHz}-\mathrm{Hz}$ may be problematic as it requires knowledge of the attenuation over broad frequency band (or equivalently the quality factor $Q_{\mu}$ ). There is no unique model of the attenuation for the lower mantle. For instance, a constant value of $Q_{s}\left(=Q_{\mu}\right)$ of 312 is associated with the PREM model (Dziewonski \& Anderson 1981), while model SL8 by Anderson \& Hart (1978) suggests a radial profile with values of $Q_{s}$ increasing from 250 at the top of the lower mantle to 520 above the $\mathrm{D}^{\prime \prime}$. Various seismically obtained radial profiles of $Q_{s}$ have been reviewed by Romanowicz $\&$ Durek (2000). In this paper, we use an average value of 350 to account for the attenuation of body waves in the mantle. Assuming that the lower-mantle material is a Poisson-like solid, that is, that the compressional quality factor $Q_{\kappa}$ is very large, then $Q_{p}$ is directly obtained from $Q_{s}$ as follows: $Q_{p}=(3 / 4)\left(V_{p} / V_{s}\right)^{2} Q_{s}$ (e.g. Anderson \& Hart 1978). In order to correct the seismic wave velocities for attenuation at a given frequency $\omega$ we use the formula proposed by Minster \& Anderson (1981):

$V_{s, p}(\omega)=V_{s, p}^{u}\left[1-\frac{1}{2} \operatorname{cotan}\left(\frac{\beta \pi}{2}\right) \frac{1}{Q_{s, p}(\omega)}\right]$,

where $V_{s, p}^{u}$ are the unrelaxed (elastic) seismic velocities, and $\beta$ is a numerical factor related to the material properties. The value of $\beta$ in the lower mantle is not precisely determined and experimental studies indicate that its value is between 0.2 and 0.4 (e.g. Karato \& Spetzler 1990). In this study, we assume an average value of 0.3 .

\subsubsection{Perovskite}

The shear modulus $\mu_{0}$ of $\mathrm{MgPv}$ has been measured by several authors, using Brillouin spectroscopy (Yeganeh-Haeri et al. 1989; Murakami et al. 2007; Sinogeikin et al. 2004) or ultrasonic measurements (Sinelnikov et al. 1998; Aizawa et al. 2004). Li \& Zhang (2005) performed measurements by ultrasonic interferometry in conjunction with X-ray diffraction. Values of $\mu_{0}$ obtained in the these studies is consistently close to $175 \mathrm{GPa}$. The deviations from this value do not exceed $4 \mathrm{GPa}$. Compatible values of $\mu_{0}$ have been observed both on a single crystal and on a powder sample. The theoretical studies by Kiefer et al. (2002) and Oganov et al. (2001) give similar results. The temperature and pressure dependence of $\mu_{0}$ were studied by Sinelnikov et al. (1998) and by Li \& Zhang (2005) up to $900 \mathrm{~K}$ and $9 \mathrm{GPa}$. These studies provided values of $\mu_{0}^{\prime}$ of $1.8 \pm 0.4$ and $2.0 \pm 0.1$. In the most recent study, Murakami et al. (2007) conducted measurements to very high pressures (close to $100 \mathrm{GPa}$ ) and obtained a significantly lower value of the pressure derivative, $\mu_{0}^{\prime}=1.56 \pm 0.04$, than the previous studies. Several theoretical studies, for example, Wentzcovitch et al. (2004), Kiefer et al. (2002), Matsui (2000) and Cohen (1987), have discussed the pressure and temperature derivatives of Mg-perovskite. The values reported in these papers are within the uncertainties reported 
in by the experimental studies. The effect of iron and aluminum on the shear properties of perovskite have been studied by Kiefer et al. (2002) from ab initio simulations. They concluded that adding $25 \mathrm{~mol}$ per cent of Fe into $\mathrm{MgPv}$ decreases $\mu_{0}$ by 6 per cent and $\mu_{0}^{\prime}$ (i.e. the pressure derivative of $\mu_{0}$ ) by 8 per cent. The fact that substitution of ferrous-iron into a magnesium-rich mineral decreases its shear modulus is broadly consistent with elasticity-composition trends (Duffy \& Anderson 1989). Recently, Jackson et al. (2004) measured the shear modulus of perovskite with $5 \mathrm{~mol}$ per cent of $\mathrm{Al}_{2} \mathrm{O}_{3}$. They observed a decrease of 6 per cent in $\mu_{0}$ suggesting that the substitution of magnesium by aluminum has a stronger effect than substitution for iron. Jackson et al. (2005) have also studied the pressure derivative of the shear modulus in $\mathrm{MgSiO}_{3}$-perovskite containing $5.5 \mathrm{wt}$ per cent of $\mathrm{Al}_{2} \mathrm{O}_{3}$; they obtained a value of $1.7 \pm$ 0.2 which is within the experimental uncertainties of values measured by Sinelnikov et al. (1998) and by Murakami et al. (2007) for a pure magnesium perovskite. This suggests that the substitution for aluminum does not significantly affect the pressure derivative of silicate perovskite.

\subsubsection{Magnesiowüstite}

As with the EoS parameters, the shear modulus of magnesiowüstite is better constrained than that of perovskite through multiple measurements using several methods. The value of $\mu_{0}$ has been measured by Jacobsen et al. (2002), Sinogeikin \& Bass (2000), Bonczar \& Graham (1982) and Jackson \& Niesler (1982), its pressure and temperature derivatives were measured by Sinogeikin \& Bass (2000) and Jackson \& Niesler (1982). The results from theoretical calculations (Karki et al. 1999) and from computations using parametrized pair-potentials (Matsui 2000) agree with experimental observations, and the associated uncertainties are smaller by a factor of 2 compared with perovskite (see Table 1). The shear modulus of a non-stoichiometric wüstite has been measured by Jackson et al. (1990) and by Sumino et al. (1980). Recently Kantor et al. (2005) showed that the shear properties of $\mathrm{FeO}$ are likely influenced by pressure induced magnetization. Since we only consider magnesium-rich compositions relevant to the lower mantle (presumably not more than $30 \mathrm{~mol}$ per cent of $\mathrm{FeO}$ ), we are not concerned with details of the complex behaviour of non-stoichiometric wüstite. We adopt the value of $46 \mathrm{GPa}$ for $\mu_{0}$ obtained by Jackson et al. (1990). This value is consistent with observations of $\mu_{0}$ for magnesiowüstite samples with various concentration of iron, performed by Jackson et al. (2005), Jacobsen et al. (2002), Kung et al. (2002), Bonczar \& Graham (1982) and Jackson et al. (1978). Jackson et al. (2005) studied the effect of iron and determined a $\mu^{\prime}$ of $2.1 \pm 0.1$ for $6 \mathrm{~mol}$ per cent of $\mathrm{FeO}$. Kung et al. (2002) measured a $\mu_{0}^{\prime}$ of $1.9 \pm$ 0.1 for $17 \mathrm{~mol}$ per cent of $\mathrm{FeO}$ in $\mathrm{Mw}$. These results, compared to $\mu^{\prime}=2.2 \pm 0.1$ obtained by Sinogeikin \& Bass (2000) for pure $\mathrm{MgO}$, indicate that the substitution of magnesium by iron likely decreases the pressure derivative of the shear modulus for magnesiowustite. This is in agreement with observations of $\mathrm{FeO}$ by Jackson et al. (1990) and Kantor et al. (2005) who obtained $\mu_{0}$ values of 0.7 and 0.6 , respectively. Concerning the influence of iron on the temperature derivative of shear modulus, Bonczar \& Graham (1982) have suggested that $\left(\partial \mu_{0} / \partial T\right)_{P}$ would increase with the iron concentration, giving a positive value for the wüstite end-member. Due to the scarcity of data and significant experimental uncertainties, we assume that iron has no effect on temperature derivatives of shear modulus within the relevant lower-mantle compositions.

\subsubsection{Calcium perovskite}

There are no experimental data on the shear modulus for $\mathrm{CaPv}$. Since it is a non-quenchable phase, its properties can only be measured within its $P-T$ stability field. As discussed above, this is difficult from a technical point of view. Duffy \& Anderson (1989) have determined shear properties based on systematics and Karki \& Crain (1998) have performed ab initio calculations. We adopt the latter values as a preferred set.

\section{MODEL PARAMETERS, OBSERVATIONS AND INVERSION TECHNIQUE}

Radial profiles of bulk properties, such as density and seismic velocities, reflect both the composition and the thermal structure of the lower mantle. The observed values of these properties can, therefore, be used in order to extract information on average lower-mantle composition and temperature.

We first define the forward problem that relates any set of model parameters (a vector $\mathbf{p}$ ) to a set of predictions (a calculated synthetic data vector $\mathbf{d}$ ), that is generally different from the observed data, $\mathbf{d}_{0}$; it can be mathematically expressed as $\mathbf{d}=\mathbf{g}(\mathbf{p})$. The operator $\mathbf{g}$ represents the physical theory that allows us to compute the density $\rho$ and seismic velocities $V_{p}$ and $V_{s}$ (i.e. vector d) from a given model of mantle mineralogy, temperature and an elasticity data set (i.e. vector $\mathbf{p}$ ). It corresponds to a sequence of thermodynamic operations: (1) A model of bulk chemical composition, expressed in proportions of oxide components, is transformed into the molar proportions of the six mineralogical end-members using mass balance constraint and the iron partition coefficient $K_{D}$ between perovskite and magnesiowüstite phases. The exact value of $K_{D}$ in presence of all major elements is not precisely determined (e.g. Wood \& Rubie 1996). Mattern et al. (2005) pointed out that the value of $K_{D}$ at thermodynamic equilibrium is almost constant (varying between 0.8 and 1.2) throughout the portion of the lower mantle considered here. In this study, we use a fixed average value of $K_{D}=1$ but the effect of varying $K_{D}$ between 0.5 and 2 is also discussed. (2) Elastic properties of each mineralogical end-member (Tables 1 and 2) are extrapolated to lower-mantle conditions using relevant equation of state and (3) The Reuss-Voigt-Hill averaging scheme is used to obtain the density and the seismic velocities of the assemblage. The analytical form of $\mathbf{g}$ is described in Appendices A, B and D.

In the simplest cases, the model parameters $\mathbf{p}$ are five molar proportions of the simple oxides $\mathrm{MgO}, \mathrm{FeO}, \mathrm{Al}_{2} \mathrm{O}_{3}, \mathrm{CaO}$ and $\mathrm{SiO}_{2}$,

Table 2. Thermal parameters of Mie-Grüneisen EoS - Debye temperature, $\Theta_{D_{0}}$, and its derivatives, $\gamma_{0}$ and $q_{0}$ for lowermantle minerals.

\begin{tabular}{lccc}
\hline & $\begin{array}{c}\Theta_{D_{0}} \\
(\mathrm{~K})\end{array}$ & $\gamma_{0}$ & $q_{0}$ \\
\hline $\mathrm{MgPv}\left(\mathrm{MgSiO}_{3}\right)$ & $1070^{1}$ & 1.48 & 1.4 \\
$\mathrm{FePv}\left(\mathrm{FeSiO}_{3}\right)$ & $841^{1}$ & 1.48 & 1.4 \\
$(\mathrm{Mg}, \mathrm{Al}) \mathrm{Pv}{ }^{b}$ & $1021^{1}$ & 1.48 & 1.4 \\
Periclase $(\mathrm{MgO})$ & $673^{2}$ & 1.41 & 1.3 \\
Wustite $(\mathrm{FeO})$ & $673^{2}$ & 1.41 & 1.3 \\
$\mathrm{CaPv}(\mathrm{CaSiO}$ & & 1.53 & 1.6 \\
\hline
\end{tabular}

${ }^{a}$ Same as the Mg-bearing end-member; ${ }^{b}$ Al-bearing

$\mathrm{MgSiO}_{3}$ perovskite with $5 \mathrm{~mol}$ per cent $\mathrm{Al}_{2} \mathrm{O}_{3}$.

Sources: ${ }^{1}$ See Stixrude \& Lithgow-Bertelloni (2005) and

${ }^{2}$ See Jackson (1998). 
Table 3. Three a priori models of lower-mantle bulk composition, in molar proportions of compounding oxides, used in this study. Modified pyrolite (M-Pyrolite), harzburgite and MORB compositions are also listed for comparison.

\begin{tabular}{lrrrrrrr}
\hline & $\mathrm{MgO}$ & $\mathrm{FeO}$ & $\mathrm{Al}_{2} \mathrm{O}_{3}$ & $\mathrm{CaO}$ & $\mathrm{SiO}_{2}$ & $\mathrm{Mg} / \mathrm{Si}$ & $\mathrm{Fe} / \mathrm{Si}$ \\
\hline Pyrolite $^{1}$ & 0.494 & 0.063 & 0.022 & 0.032 & 0.389 & 1.272 & 0.162 \\
Chondritic $^{2}$ & 0.468 & 0.053 & 0.018 & 0.026 & 0.435 & 1.073 & 0.121 \\
Cosmic $^{3}$ & 0.470 & 0.035 & 0.017 & 0.022 & 0.456 & 1.031 & 0.077 \\
M-Pyrolite $^{4}$ & 0.523 & 0.066 & 0 & 0 & 0.411 & 1.272 & 0.161 \\
Harzburgite $^{5}$ & 0.572 & 0.061 & 0.003 & 0.004 & 0.360 & 1.589 & 0.168 \\
MORB $^{5}$ & 0.158 & 0.070 & 0.101 & 0.147 & 0.522 & 0.303 & 0.134
\end{tabular}

Sources: ${ }^{1}$ Jackson \& Ridgen (1998); ${ }^{2}$ Hart \& Zindler (1986); ${ }^{3}$ Anderson \& Bass (1986); ${ }^{4}$ modified pyrolite, $\mathrm{Mg} / \mathrm{Si}=1.27, \mathrm{Fe} /(\mathrm{Mg}+\mathrm{Fe})=0.113$ and

${ }^{5}$ Ringwood (1991).

with the constraint that the sum of molar proportions is equal to 1 implicitly built into the inversion procedure. In the following computations, we consider three bulk compositions: pyrolite (e.g. Jackson \& Ridgen 1998), chondritic (C1 model of Hart \& Zindler 1986) and cosmic (Anderson \& Bass 1986). These three compositional models are the results of different approaches used to construct a model for the bulk Earth composition. The pyrolite model is a silica-depleted model, consistent with the sampled values of sublithospheric $\mathrm{Mg} / \mathrm{Si}$ ratio whereas the chondritic and cosmic models are silica-rich compositions with $\mathrm{Mg} / \mathrm{Si}$ ratio close to 1 . In terms of major elements the latter two models differ in their iron content: the $\mathrm{Fe} / \mathrm{Si}$ ratio of the cosmic model is significantly lower than that of the pyrolite and chondritic models. The chemical composition (in mole fractions of five major simple oxides) of the three compositional models are listed in Table 3. When these compositions are used as initial guesses, the a priori confidence is expressed by assuming Gaussian bounds for each component. Since there is no straightforward way to estimate these bounds, we choose the $1 \sigma$ Gaussian bounds to be twice the largest difference among the three compositional models. These a priori uncertainties are chosen to ensure that a broad range of compositional space is considered in the inversion, while allowing us to discard unrealistic compositions such as very low $\mathrm{MgO}$ or very high $\mathrm{CaO}$ models. Since the a priori uncertainties for the three models overlap, we do not build in a strong bias for any of the three a priori models.

The temperature is an additional model parameter. In all computations presented in this study the a priori thermal profile is the geotherm given by Brown \& Shankland (1981). Our confidence in the initial temperature profile is modelled by a priori Gaussian standard deviations that increase linearly from $\pm 200 \mathrm{~K}$ at $800 \mathrm{~km}$ to $\pm 1000 \mathrm{~K}$ at $2700 \mathrm{~K}$. The smaller uncertainty on the temperature at the top of the lower mantle is necessary to have the ringwoodite to perovskite plus magnesiowüstite phase change occur at $660-\mathrm{km}$ depth. Of course, if the Clapeyron slope of this phase transition is close to zero at high-temperature, as suggested by Katsura et al. (2003), such a constraint may be too strong. We note however that the $660-\mathrm{km}$ discontinuity is complex region associated with multiple phase changes with different Clapeyron slopes (e.g. Hirose 2002). In this study, we only consider the lower mantle depth range between 800 and $2700 \mathrm{~km}$. In doing so, we avoid including mineralogically complex zones associated with a broad garnet-to-perovskite phase change that may extend down to $750 \mathrm{~km}$ (e.g. Hirose 2002), and with the perovskite-to-post-perovskite phase change in the lowermost mantle (Murakami et al. 2004).

A so-called adiabatic geotherm, often used as a reference mantle temperature profile, assumes that the convective mantle is homo- geneous and adiabatic. This first assumption is violated when the chemical composition is variable and the second assumption is violated in a non-Boussinesq internally heated fluid (e.g. Bunge et al. 2001). A constraint of the Earth density profile is given by the observation of the Bullen parameter $\eta$ (Bullen 1963),

$\eta=V_{\phi}^{2}\left(\frac{d \rho}{d r}\right)\left(\frac{d P}{d r}\right)^{-1}$,

where the bulk sound velocity $V_{\phi}\left(V_{\phi}^{2}=V_{p}^{2}-4 / 3 V_{s}^{2}\right)$ is deduced from a radial body-wave model, and $(d \rho / d r) /(d P / d r)$ reflects the actual density-pressure relationship along a radial profile of the Earth. This relationship, given by models like PREM and ak135, is constrained by normal modes measurements, and by the astronomical knowledge of the mass and inertia of the Earth in addition to body-wave traveltimes. The Bullen parameter is observed to be $1 \pm$ 0.02 .

In a homogeneous mantle, the departure of $(d \rho / d r) /(d P / d r)$ from the adiabatic value $(\partial \rho / \partial P)_{S}=V_{\phi}^{-2}$ can only be due to the fact that the mantle geotherm $(d T / d r)_{E}$ is not adiabatic and one has

$\left(\frac{d \rho}{d r}\right)\left(\frac{d P}{d r}\right)^{-1}=V_{\phi}^{-2}+\frac{\alpha}{\rho g}\left[\left(\frac{d T}{d r}\right)_{E}+\frac{\alpha g T}{C_{p}}\right]$,

where $\alpha, C_{p}$ and $g$ are the thermal expansion, the specific heat, and the gravitational acceleration, respectively. The Bullen parameter would, therefore, be $\eta_{H}$ where

$\eta_{H}=1+V_{\phi}^{2} \frac{\alpha}{\rho g}\left[\left(\frac{d T}{d r}\right)_{E}+\frac{\alpha g T}{C p}\right]$,

and $\eta_{H}=1$ in a homogeneous mantle implies a so-called adiabatic geotherm defined by

$\left(\frac{d T}{d r}\right)_{E}+\frac{\alpha g T}{C_{p}}=0$.

In an inhomogeneous Earth, however, $(d \rho / d r) /(d P / d r)$ differs from $V_{\phi}^{-2}$ not only because of thermal effect but also because of the compositional gradient. In presence of a compositional gradient, the Bullen parameter $\eta=1$ does not imply a geotherm that obeys eq. (5). Reciprocally, if the geotherm follows eq. (5), then $\eta_{H}$ equals 1 but $\eta$ is not necessarily 1 . In our inversions we will check that the inverted temperature and compositional profiles yield a Bullen parameter $\eta$ close to 1 (as observed) and $\eta_{H}$ is used as a measure of the departure of the inverted geotherm from a geotherm obeying eq. (5).

The data, $\mathbf{d}_{0}$, are the density $\rho$ and seismic velocities $V_{p}$ and $V_{s}$. We use the values reported in the seismic model ak135 (Kennett et al. 1995). In some numerical experiments (see Appendix C), we use the bulk sound velocity $V_{\phi}$ instead of seismic velocities. The following amplitudes of the a priori uncertainties on the observations are adopted: $\delta \rho / \rho=0.5$ per cent (Masters \& Gubbins 2003), $\delta V_{p} / V_{p}=\delta V_{s} / V_{s}=0.2$ per cent. These amplitudes correspond to the maximum uncertainties on seismic velocities estimated by Kennett et al. (1995). We note that the differences between ak135 and other radial seismic models-PREM (Dziewonski \& Anderson 1981), IASP91 (Kennett \& Engdahl 1991) and sp6 (Morelli \& Dziewonski 1993) - are smaller than these uncertainties. In the case of the bulk sound velocity $V_{\phi}$ which is derived from $V_{p}$ and $V_{s}$ (both subject to an uncertainty of 0.2 per cent), we adopt an uncertainty of 0.4 per cent for $V_{\phi}$.

We then formulate an inverse problem to find a set of model parameters, $\hat{\mathbf{p}}$, that explains the selected observations, $\mathbf{d}_{0}$, within their uncertainties and that remains reasonably close to an a priori guess of model parameters (a vector $\mathbf{p}_{0}$ ). The result of the inverse 
problem, $\hat{\mathbf{p}}$, corresponds to the minimum of the following misfit function:

$\mathbf{S}(\mathbf{p})=\left[\mathbf{d}_{0}-\mathbf{g}(\mathbf{p})\right]^{\mathrm{T}} \mathbf{C}_{\mathbf{d}_{0} \mathbf{d}_{0}}^{-1}\left[\mathbf{d}_{0}-\mathbf{g}(\mathbf{p})\right]+\left(\mathbf{p}-\mathbf{p}_{0}\right)^{\mathrm{T}} \mathbf{C}_{\mathbf{p}_{0} \mathbf{p}_{0}}^{-1}\left(\mathbf{p}-\mathbf{p}_{0}\right)$,

where $\mathbf{C}_{\mathrm{d}_{0} \mathrm{~d}_{0}}$ and $\mathbf{C}_{\mathrm{p}_{0} \mathrm{p}_{0}}$ are covariance matrices corresponding to our a priori confidence in the data and a priori knowledge of model parameters. We assume that data and parameters are uncorrelated. Therefore, the covariance matrices are diagonal and contain the squares of uncertainties on observations, $\mathbf{C}_{\mathrm{d}_{0} \mathrm{~d}_{0}}$, and on parameters, $\mathbf{C}_{\mathrm{p}_{0} \mathrm{p}_{0}}$. The minimization is performed iteratively using standard numerical procedures (for details see Tarantola \& Valette 1982). Besides yielding the best-fitting model $\hat{\mathbf{p}}$, the use of generalized inverse theory provide a tool to evaluate the associated a posteriori uncertainties of best-fitting model parameters. It also gives the a posteriori covariance matrix that indicates how strongly the resulting parameter are correlated, and the resolution matrix that determines individually for each parameter whether or not the inversion was successful in matching the observation within their uncertainties.

In order to evaluate how successful an inversion is, one can compute the associated $\chi$-factor defined as follows:

$\chi=\sqrt{\frac{1}{N_{D}} \sum\left(\frac{d_{i}-d_{0_{i}}}{\Delta d_{i}}\right)^{2}}$,

where $N_{D}$ is number of predicted observables; $d_{i}, d_{0_{i}}$ are elements of the prediction and observable vectors $\mathbf{d}, \mathbf{d}_{0}$, respectively; $\Delta d_{i}$ are the a priori uncertainties on the observables $\mathbf{d}_{0}$. If the $\chi$-factor is larger than one, the inversion is not successful, the resulting deviations are on average larger than the a priori uncertainties.

\section{RESULTS}

Fig. 1 shows the differences between predicted and observed $V_{p}$ and $V_{s}$ for the three a priori compositional models before performing the inversion. Assuming Brown and Shankland's geotherm and pyrolite model, the predicted seismic velocities are lower then those from ak135 in the top $700 \mathrm{~km}$ of the lower mantle by at most 1 per cent. They become larger below depth of $1500 \mathrm{~km}$ and the differences reach 1 and 3 per cent for $V_{p}$ and $V_{s}$, respectively, at the depth of $2700 \mathrm{~km}$. For comparison we also plot the results for a modified pyrolite model (M-pyrolite) that does not contain any $\mathrm{Al}_{2} \mathrm{O}_{3}$ and $\mathrm{CaO}$ but has identical $\mathrm{Mg} / \mathrm{Si}$ and $\mathrm{Fe} /(\mathrm{Mg}+\mathrm{Fe})$ ratios as the pyrolite (see Table 3). A comparison of these two pyrolite models shows that with $\mathrm{Ca}$ and $\mathrm{Al}$ not included, the predicted velocities of the model assemblage (in this case, pyrolite) are significantly higher, especially in the upper half of the lower mantle. When the chondritic or cosmic models are adopted, the computed discrepancies are always higher and they increase with depth. In the case of $V_{p}$, they reach 2 and 3 per cent, respectively, at the depth of $2700 \mathrm{~km}$. The predicted deviations for $V_{s}$ are larger by 1.5 per cent compared to those for $V_{p}$. The mismatch between the predicted and observed profiles can be quantified by using the $\chi$-factor. For all the compositional models we consider, its values are always significantly larger than one: $\chi=5.34,7.31,10.92$ and 6.42 , for pyrolitic, chondritic, cosmic and modified pyrolite compositional models, respectively.

The discrepancies between the predicted and observed velocities can be reduced in several ways. From Fig. 1 we can see that a better agreement should be obtained (1) if the optimized geotherm has a larger gradient than that of Brown and Shankland, (2) if the composition is allowed to vary with depth and (3) if the pressure derivative of shear modulus for the mineral assemblage is lower than
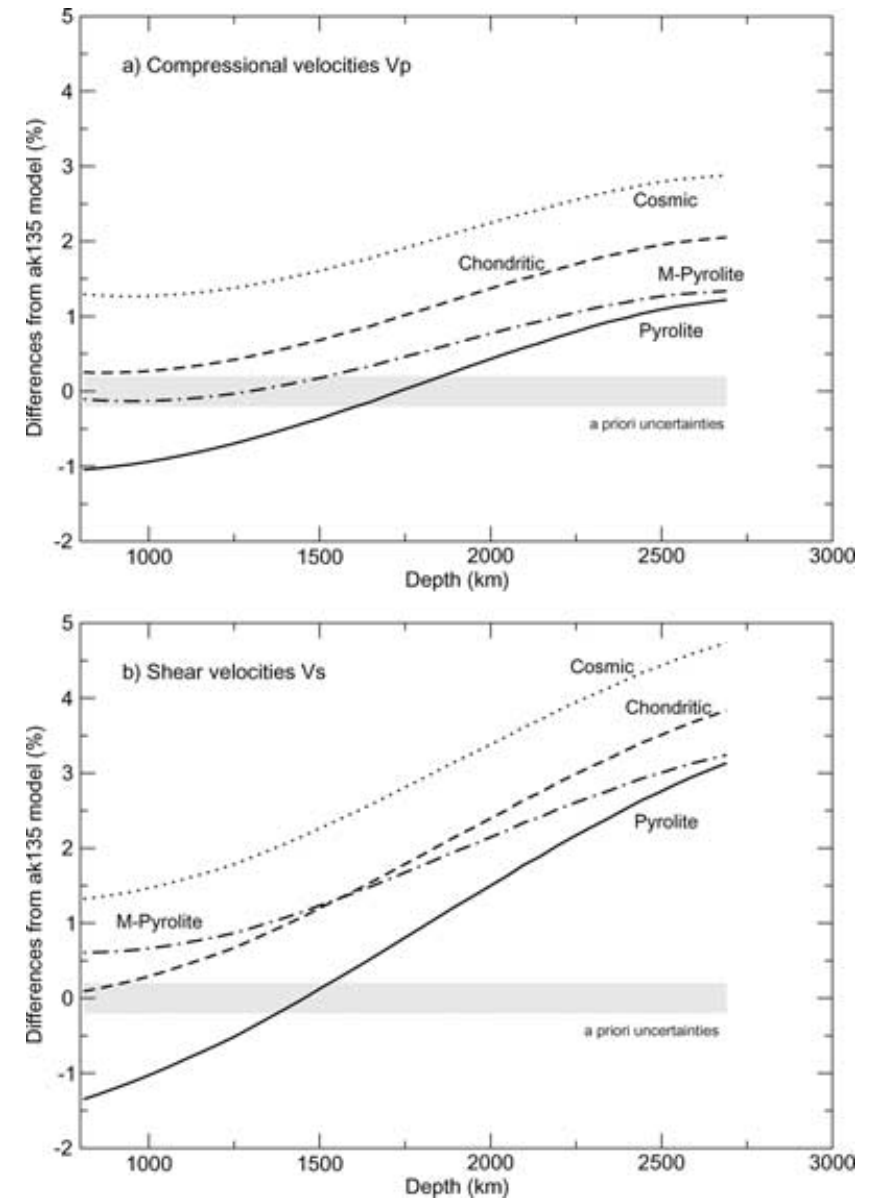

Figure 1. Differences between predicted and observed seismic velocities $V_{p}$ (a) and $V_{s}$ (b) for a lower mantle having uniform bulk composition model together with the Brown and Shankland's geotherm: pyrolite (solid line), modified pyrolite (dot-dashed line), chondritic model (dashed line), cosmic model (dotted line). The predicted velocities are always higher than those given by ak135, except for the top $400 \mathrm{~km}$ when the pyrolitic model is used. The discrepancy increases with depth and reaches 3 and 4 per cent for $V_{p}$ and $V_{s}$, respectively, in the bottom of the lower mantle. The predicted discrepancies are significantly larger than the uncertainties on the radial seismic profiles (denoted by the shaded areas).

that used in the initial model. The shear moduli appear to be more important than the bulk moduli because the discrepancies for $V_{s}$ are larger than those for $V_{p}$. We note that the partition coefficient of iron, $K_{D}$, has only a minor effect on these results: for instance in the case of $V_{s}$, varying its values between 0.5 and 2 yields modifications of about \pm 0.05 per cent compared to a value obtained with $K_{D}$ equal 1. This indicates that the partition coefficient is not a dominant parameter in modelling the velocity structure of the lower mantle.

\subsection{Inversions for geotherm assuming uniform bulk composition, with fixed elastic parameters}

In order to compare our inversion with previous studies with fixed compositions, we first impose four different compositional models - pyrolite, chondritic cosmic and modified pyrolite (see Table 3). Three independent observations $\left(\rho, V_{p}\right.$ and $\left.V_{s}\right)$ are considered and we only solve for the geotherm. The resulting geotherms are shown in Fig. 2; the initial Brown and Shankland's geotherm and its uncertainties are depicted by a light shading. The inverted geotherms 


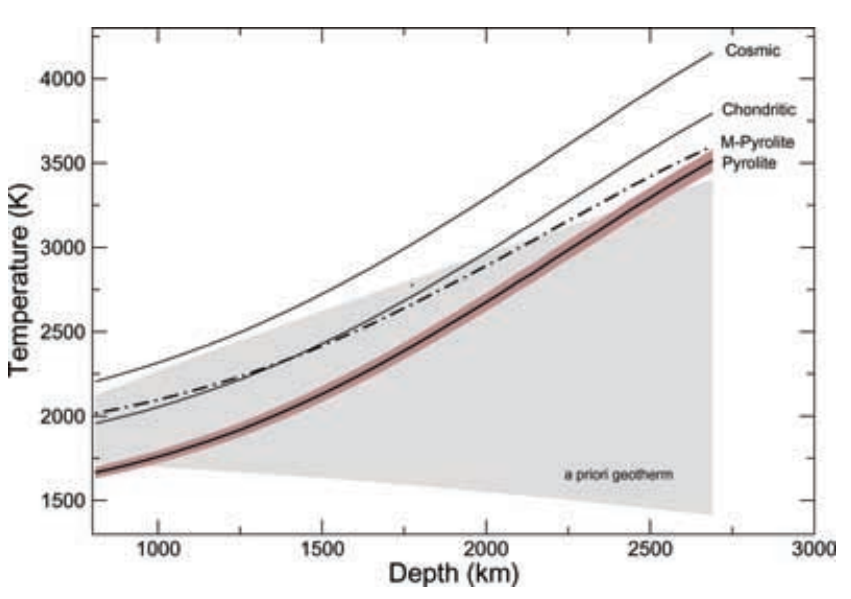

Figure 2. Best-fitting geotherms and their resulting uncertainties associated with fixed bulk composition when using density $\rho$ and seismic velocities $V_{p}$ and $V_{s}$ as observables. The initial geotherm from Brown \& Shankland (1981) and the a priori Gaussian bounds are denoted by the light shading. The four different compositional models yield four different geotherms, all of them are superadiabatic. The a posteriori uncertainties are depicted by the dark shading.

are superadiabatic and different for each bulk composition, that is, the choice of a priori model affects the resulting model. The optimized geotherms exceed $3400 \mathrm{~K}$ at the depth of $2700 \mathrm{~km}$. This temperature does not take into account the thermal boundary layer across which a further $\sim 1000 \mathrm{~K}$ increase is expected (e.g. Anderson 1989). We note that a similar result was also obtained by da Silva et al. (2000). The a posteriori uncertainties (depicted by the dark shading in the case of pyrolitic composition) are significantly smaller than the a priori ones and the resulting geotherms do not overlap within the a posteriori bounds. In the case of pyrolite, the upper part of the lower mantle is cold and the geotherm obtained for the cosmic compositional model is significantly hotter than any other solution. However, only for the chondritic model are the density and seismic velocities of ak 135 matched with a $\chi$-factor lower than one $(\chi$-factor $=1.27,0.76,2.04,1.44$, for pyrolitic, chondritic, cosmic and modified pyrolite models, respectively).

In Fig. 3(a) (dashed line) we depict the Bullen parameter $\eta$ (in this homogeneous case $\eta=\eta_{H}$ ) associated with the pyrolitic model. Computed Bullen parameter decreases from 0.98 at $800 \mathrm{~km}$ to 0.90 at $2700 \mathrm{~km}$ which is significantly different from that deduced from the ak135 model (solid line in Fig. 3a). We obtain almost identical results for the chondritic composition. It indicates that the solutions found by our inversion are not fully compatible with all available seismological observations. This conclusion reinforces the results of Cammarano et al. (2005), who showed that only very restricted set of models for the elastic properties would match a homogenous adiabatic mantle.

\subsection{Inversions for geotherm and bulk composition, with fixed elastic parameters}

In order to investigate possible depth dependent compositional models, we now consider six model parameters (temperature and five proportions of oxide components) at each depth. The three different compositional models - pyrolite, chondritic and cosmic (see Table 3) - are now used as a priori guesses with their error bars. In Fig. 4, we show the resulting temperature profiles and proportions of the oxide components. The resulting $\chi$-factors are now smaller than
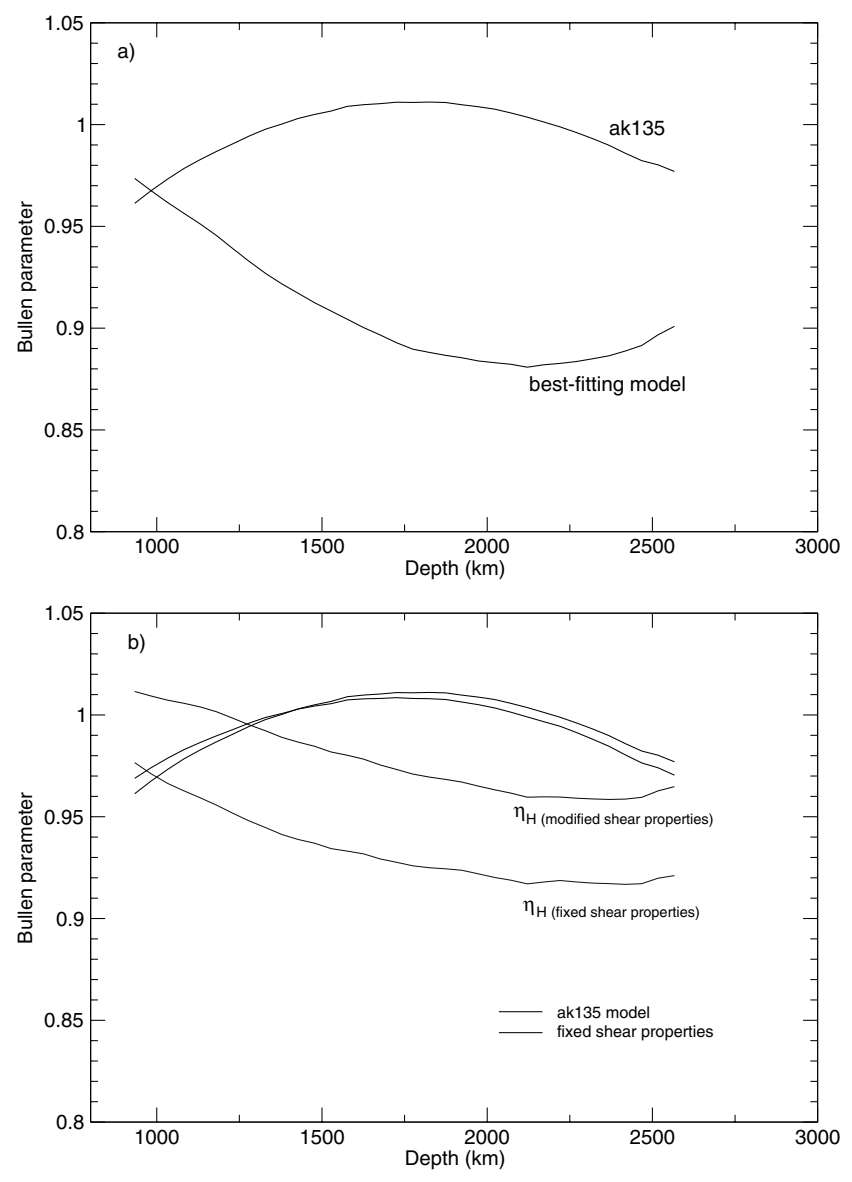

Figure 3. Bullen parameter as a function of depth. (a) Assuming uniform pyrolite (or chondritic) composition, values of the Bullen parameter are significantly lower from those obtained for ak 135 below the depth of 1000 km. (b) For inversions with depth dependent bulk composition with fixed shear properties, the resulting values of $\eta$ (solid line) matches the values obtained from ak135 (dashed line) within \pm 1 per cent. The values of $\eta_{H}$ (dot-dashed line) are, however, always lower, varying between 0.97 and 0.92 , than those of $\eta$. When the shear properties are allowed to vary, the resulting $\eta$ matches $\eta$ of ak135 perfectly. In this case, $\eta_{H}$ (dotted line) is decreasing with depth: it is higher than 1 down to $1200 \mathrm{~km}$ and reaches 0.97 in the bottom of the lower mantle.

in the previous case, close to 0.1 (i.e. the three best-fitting models explain the observations equally well). Although the inverse problem is underdetermined, the three inversions with different initial compositions converge to essentially the same solutions for geotherm and composition. For the visual clarity of our figures, we plot only the results obtained when the pyrolitic model is used as the initial guess, and the a posteriori uncertainties are depicted by the dark shading.

The optimized geotherms have a posteriori uncertainties larger than in the previous computation because the number of model parameters has increased from 1 to 6 . The temperature gradients are significantly larger than in the starting Brown and Shankland's geotherm: $d T / d z$ increases from $0.5 \mathrm{~K} \mathrm{~km}^{-1}$ at $800 \mathrm{~km}$ to $0.9 \mathrm{~K} \mathrm{~km}^{-1}$ at $2700 \mathrm{~km}$, where the temperature exceeds $3300 \mathrm{~K}$. Since the chemical composition is allowed to vary with depth, the resulting geotherm cannot be simply associated with a superadiabat (see the discussion of the Bullen parameter $\eta$ in the previous section). The resulting values of $\eta$ are close to 1 and match the values obtained for the ak135 model within \pm 1 per cent (solid line in 
Fig. 3b). The values of $\eta_{H}$ are, however, significantly lower than 1 and they decrease from 0.98 and 0.92 (dashed line in Fig. 3b). This results illustrates that a geotherm with large temperature gradient (i.e. a geotherm that would be called super-adiabatic if eq. (5) were used) may yield a seismically derived values of Bullen parameter $\eta$.

When the modified pyrolite composition (with no aluminum and no calcium as often assumed in previous studies) is used, we obtain a geotherm that is hotter by about $300 \mathrm{~K}$ (dot-dashed line in Fig. 4a) than in the case of pyrolite composition. These differences are significant because they exceed the a posteriori uncertainties of the best-fitting geotherm. They illustrate the non-negligible effect of correlations between composition and temperature, and possible shortcomings when simplified bulk compositional models are used.
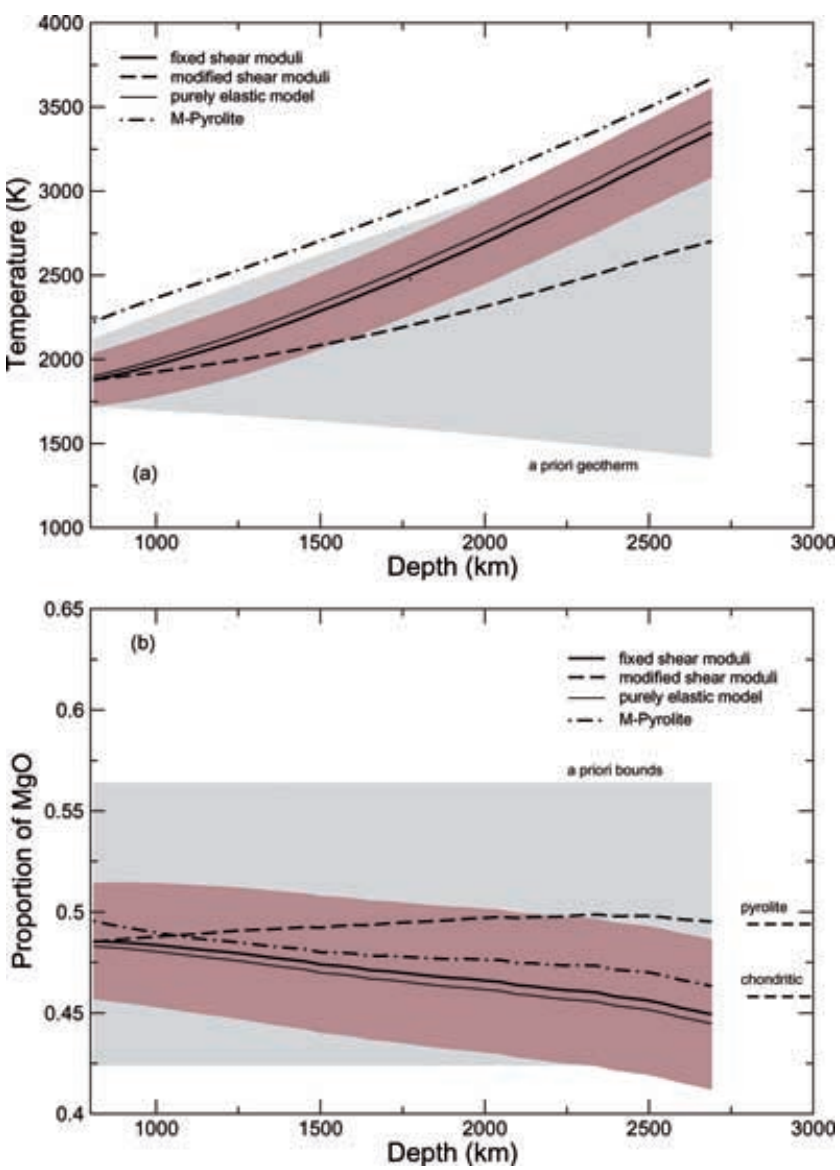

Figure 4. Resulting geotherms (a) and proportions of $\mathrm{MgO}$ (b), $\mathrm{SiO}_{2}$ (c), and $\mathrm{FeO}$ (d) when solving simultaneously for temperature and composition. The results when the pyrolitic model is used as initial guess are denoted by solid lines. The effect of anelasticity (light-solid line) is within the $a$ posteriori uncertainties (dark shading). The results for modified pyrolite are depicted by dot-dashed lines. The optimized composition is characterized by a decreasing $\mathrm{Mg} / \mathrm{Si}$ ratio (from 1.18 to 1.03 ), increasing $\mathrm{FeO}$ content, and a geotherm having larger temperature gradient that the Brown and Shankland's geotherm. In order to improve the fit, the inversion decreases the value $\mu_{0}^{\prime}$ of perovskite when the shear properties are allowed to be modified. The best matching value is 1.59 or $1.66 \pm 0.08$ (see Table 4 ). In this case, the results are denoted by the dashed lines. The resulting geotherm is closer to the Brown and Shankland's initial profile. The $\mathrm{Mg} / \mathrm{Si}$ ratio is increasing with depth (from 1.18 to 1.26 ), $\mathrm{FeO}$ content is constant with depth. The light shading denotes the initial Gaussian bounds on the temperature and compositional parameters. The proportions of $\mathrm{Al}_{2} \mathrm{O}_{3}$ and $\mathrm{CaO}$ are not shown because they are only poorly resolved.
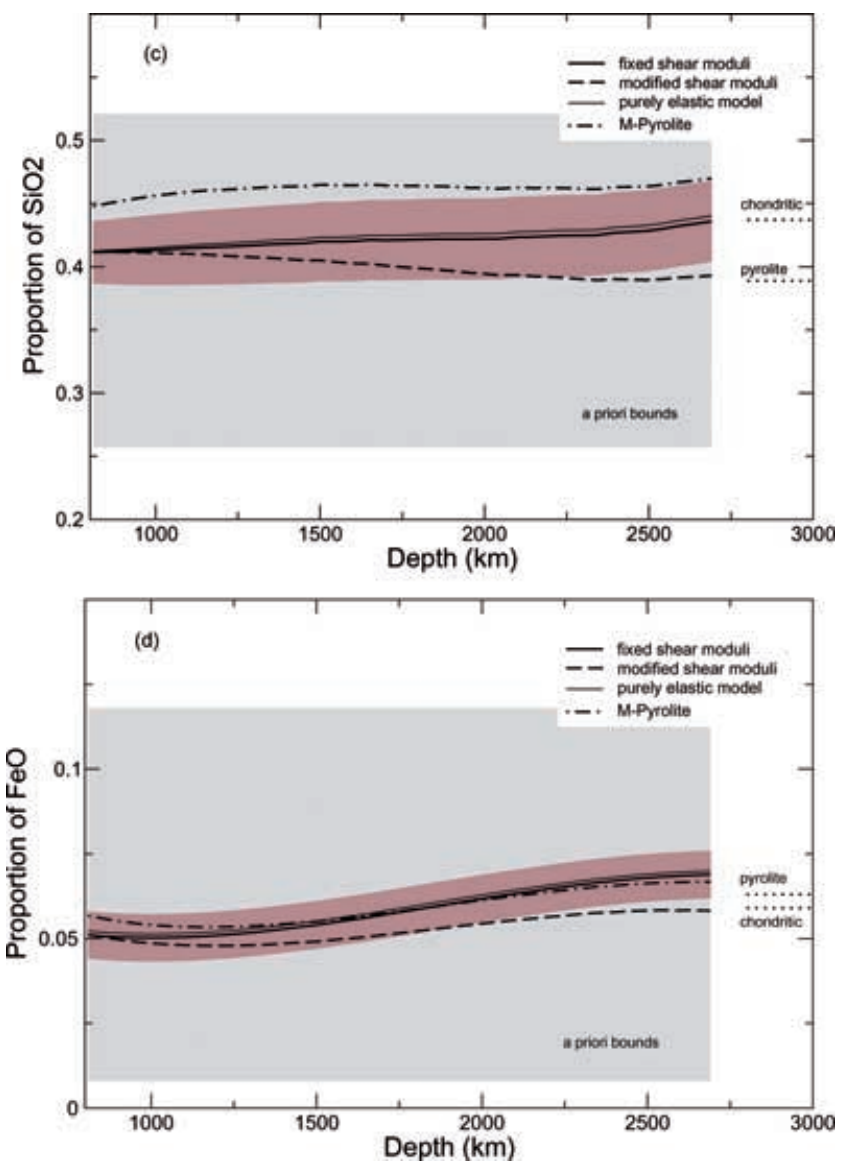

Figure 4. (Continued.)

We have also tested the effect of anelasticity (the quality factor $Q_{\mu}$ ) on the resulting profiles by setting $Q_{\mu}$ to infinity. In this case, we obtain a geotherm hotter by $70 \mathrm{~K}$ compared to the anelastic one. Although this difference is not significant compared to the a posteriori uncertainties, it is of the same order as the difference between the best-fitting models obtained for different initial guesses for the bulk composition.

The optimized depth-dependent composition as well as the a posteriori uncertainties returned by the inversion are shown in Figs $4 \mathrm{~b}-$ $4 \mathrm{~d}$. At the top of the lower mantle, the proportion of $\mathrm{MgO}$ is lower than the pyrolitic value but remains higher than the chondritic one. Similarly, the best-fitting $\mathrm{SiO}_{2}$ proportion is in between pyrolite and chondritic composition. The $\mathrm{Mg} / \mathrm{Si}$ ratio is $1.18 \pm 0.14$ instead of 1.27 for pyrolite and 1.05 for chondrite (see Table 3). With increasing depth the lower mantle becomes more depleted in $\mathrm{MgO}$ and enriched in $\mathrm{SiO}_{2}$. At the bottom of the lower mantle the composition is close to the chondritic model: $\mathrm{Mg} / \mathrm{Si}=1.03 \pm 0.16$. In the same figures, we have also plotted the optimized composition when the modified pyrolite model is used (dot-dashed lines). One can see that the results are similar although the $\mathrm{MgO}$ and $\mathrm{SiO}_{2}$ proportions seem to vary less with depth. Such a variable bulk composition could be interpreted as an indication either of the presence of depthdependent fraction of chondritic material in the lower mantle or of a heterogeneous segregation of the crustal $\left(\mathrm{SiO}_{2}\right.$-rich) and lithospheric $\left(\mathrm{SiO}_{2}\right.$-depleted) material brought to the lower mantle by the subducting slabs. For example an assemblage of 50 per cent pyrolite/ 50 per cent chondrite could be found down to the depth of $1300 \mathrm{~km}$ and a low $\mathrm{Mg} / \mathrm{Si}$ ratio in the lowermost mantle could indicate 


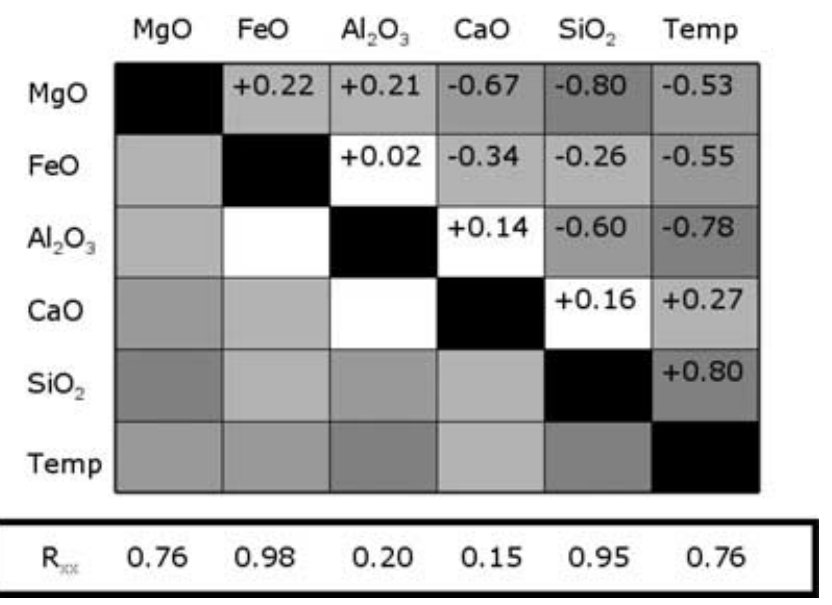

Figure 5. Resulting correlations and resolution associated with the simultaneous inversion of temperature and composition. The a posteriori covariance matrix is not diagonal indicating trade-offs between the model parameters. Their amplitudes are depicted by the grey scaling and we also show values that are greater (or lower) then $0.1(-0.1)$. It indicates that there exist a family of models that will explain equally the observables used for our inversion. $R_{x x}$ are the diagonal elements of the resolution matrix. When $R_{x x}$ is close to 1 , the parameter is well resolved, on the contrary, values close to 0 indicates the impossibility to obtain robust conclusions.

the presence of significant amount of crustal or other $\mathrm{SiO}_{2}$-rich components in a pyrolitic mantle. Taking the composition for a present day MORB, the decrease of $\mathrm{Mg} / \mathrm{Si}$ ratio from 1.18 (at the depth of $800 \mathrm{~km}$ ) to 1.03 (at $2700 \mathrm{~km}$ ) would correspond to an enrichment of the lower mantle by about 15 per cent of MORB material relative to the upper half of the lower mantle. We also observe a slight enrichment of $\mathrm{FeO}$ with depth in Fig. 4d: its proportion is $0.051 \pm 0.007$ in the upper part of the lower mantle and 0.069 \pm 0.007 at the bottom. An enrichment in $\mathrm{FeO}$ in the lower mantle was also proposed by Lee et al. (2004) who performed laboratory measurements of natural peridotites at high pressures. Such iron evolution does not seem to agree with a lower-mantle model having a bulk composition evolving toward a more chondritic material: both cosmic and chondritic compositions are more depleted in $\mathrm{FeO}$ than a pyrolite. It is more in agreement with a model where subducted MORB stagnates in the lower-most mantle.

The inversion approach allows us to compute the resulting covariance matrix (see Fig. 5) and evaluate the trade-offs between model parameters as an indication of the uniqueness of our solutions. The diagonal elements equal 1 by definition. The off-diagonal elements indicate various linear combinations of the model parameters that would yield similar fit to the observations. If the matrix were perfectly diagonal, the model parameters would not be correlated (no trade-offs would exist between them) and the obtained solution would be unique. For an underdetermined problem, the trade-offs between model parameters are inevitable. An arbitrary reduction of the number of model parameters would of course eliminate or limit these trade-offs, but would introduce a strong a priori bias to the model parameters and solutions.

The covariance matrix indicates that the strongest correlations are found between temperature and iron content, silica and magnesium oxide contents and temperature and silica content. One of the possible implications of the trade-offs between compositional parameters and temperature is illustrated by comparing the pyrolite and modified pyrolite model (Fig. 4). The differences in results are due to the strong trade-off between temperature and silica content. We also show values of diagonal elements, $R_{x x}$, of the resolution matrix in Fig. 5. These values indicate how well the different model parameters are resolved. The diagonal elements close to 1 correspond to a very good resolution, that is, significant variance reduction of the model parameter. The smaller the diagonal element, the poorer the resolution (i.e. lower variance reduction) is obtained. The best resolved compositional parameters are $\mathrm{MgO}, \mathrm{SiO}_{2}$ (associated $R_{x x}$ are close to 0.95$)$; FeO is slightly less well resolved ( $\left.R_{x x} \sim 0.88\right)$, while $\mathrm{Al}_{2} \mathrm{O}_{3}\left(R_{x x} \sim 0.25\right)$ and $\mathrm{CaO}\left(R_{x x} \sim 0.15\right)$ are not sufficiently well resolved. The resulting proportions of the latter two components are very close to the initial values for each model. The a posteriori uncertainties are as large as the a priori uncertainties and, therefore, we do not plot them in Fig. 4. The difficulty of accurately constraining the proportions of $\mathrm{Al}_{2} \mathrm{O}_{3}$ and $\mathrm{CaO}$ was also recognized by previous authors (e.g. Deschamps \& Trampert 2004; Mattern et al. 2005).

\subsection{Joint inversions of temperature, bulk composition, and shear parameters}

Up to this point, we assumed that the elastic properties of lowermantle minerals were accurately known. However, as discussed above, recent experimental results on the pressure derivatives of perovskite shear modulus give significantly different results (Li \& Zhang 2005 versus Murakami et al. 2007). In the discussion of Fig. 1, we have seen that optimization of the shear moduli of perovskite and of magnesiowüstite (in particular, their pressure derivatives) is susceptible to improve the agreement with the observed seismic velocities. Our generalized inversion approach allows us to consider the elastic parameters of mantle phases as additional model parameters. Therefore, in order to explore the full range of models that are consistent with seismological observations, we allow the shear properties of magnesium silicate perovskite and of magnesiowüstite to vary within their uncertainties. In this case $\mu_{0}$ and $\mu_{0}^{\prime}$ become part of the vector of model parameters $\mathbf{p}$ and contribute to the misfit function; that is, to the second term of the right-hand side in eq. (1). In this section and in the appendix, we also discuss the effect of uncertainties on thermal EoS parameters although it is clear that the results of our inversion are mostly affected by the pressure dependence of the perovskite shear properties.

In Fig. 4 (dashed lines), we show the optimized geotherm and composition when pyrolite is used as an initial composition. The resulting geotherm have significantly smaller temperature gradients than in the case with fixed shear properties: $d T / d z$ is $0.25 \mathrm{~K} \mathrm{~km}^{-1}$ at $800 \mathrm{~km}$ and $0.5 \mathrm{~K} \mathrm{~km}^{-1}$ at $2700 \mathrm{~km}$. This fact is reflected by higher values of $\eta_{H}$ than in the case with fixed shear properties (dotted versus dot-dashed line in Fig. 3b). The Bullen parameter $\eta$ is identical to that obtained for ak135 model (dashed line in Fig. 3b). The resulting composition (see dashed-lines in Figs $4 \mathrm{~b}-4 \mathrm{~d}$ ) significantly differ from that obtained with fixed shear properties. The vertical chemical gradients are smaller and $\mathrm{Mg} / \mathrm{Si}$ increases from $1.18 \pm 0.16$ at $800 \mathrm{~km}$ to $1.26 \pm 0.19$ at $2700 \mathrm{~km}$. The $\mathrm{FeO}$ content is essentially constant with depth and its proportion is $0.058 \pm$ 0.007 . These results are in broad agreement with those obtained by Deschamps \& Trampert (2004).

Since the shear properties are now allowed to vary, the trade-offs between the model parameters are larger compared to the previous calculations. The best-fitting profiles obtained for the three different initial guesses remain, however, similar within their a posteriori uncertainties. The resulting $\mathrm{Mg} / \mathrm{Si}$ ratio and temperature at 800 and $2700 \mathrm{~km}$ for different inversions are shown in Table 4 . When the chondritic or cosmic compositions are used as initial guess, the 
Table 4. Values of $\mathrm{Mg} / \mathrm{Si}$ ratio, temperature, and shear moduli of $\mathrm{MgSiO}_{3}$-perovskite obtained by our inversion technique in order to improve the fit to seismic velocities. The modifications of shear moduli of magnesiowüstite are negligible and are not listed here.

\begin{tabular}{|c|c|c|c|c|c|c|}
\hline & $\mathrm{Mg} / \mathrm{Si}$ & $\mathrm{T}(\mathrm{K})$ & $\mathrm{Mg} / \mathrm{Si}$ & $T(\mathrm{~K})$ & \multirow[t]{2}{*}{$\mu_{0}(\mathrm{GPa})$} & \multirow[t]{2}{*}{$\mu_{0}^{\prime}$} \\
\hline & \multicolumn{2}{|c|}{$z=810 \mathrm{~km}$} & \multicolumn{2}{|c|}{$z=2690 \mathrm{~km}$} & & \\
\hline Pyrolitic & $1.18 \pm 0.14$ & $1875 \pm 160$ & $1.26 \pm 0.19$ & $2702 \pm 300$ & $179.3 \pm 2.9$ & $1.59 \pm 0.08$ \\
\hline Chondritic & $1.16 \pm 0.14$ & $1926 \pm 160$ & $1.16 \pm 0.18$ & $2942 \pm 300$ & $177.9 \pm 2.9$ & $1.64 \pm 0.07$ \\
\hline Cosmic & $1.17 \pm 0.14$ & $1935 \pm 160$ & $1.16 \pm 0.18$ & $2972 \pm 300$ & $177.4 \pm 2.9$ & $1.66 \pm 0.07$ \\
\hline
\end{tabular}

geotherm is hotter by about $200 \mathrm{~K}$ and vertical compositional gradients are small $(\mathrm{Mg} / \mathrm{Si}$ ratio is almost constant throughout the lower mantle). We note that in all three cases, the averaged value of $\mathrm{Mg} / \mathrm{Si}$ ratio is lower that the pyrolitic one. However, due to the trade-offs, it is now difficult to propose a unique scenario in order to interpret the resulting bulk composition.

The optimized values of $\mu_{0}$ obtained for the three initial compositions are very similar; they vary from $177 \pm 3 \mathrm{GPa}$ to $179 \pm$ $3 \mathrm{GPa}$ (see Table 4). However, these values are larger than the experimental value of $173 \mathrm{GPa}$ obtained both by Li \& Zhang (2005) and by Murakami et al. (2007). Far greater modifications as well as a larger reductions in variance are observed in the case of optimized $\mu_{0}^{\prime}$. The resulting values are consistently lower than the experimental value obtained by Sinelnikov et al. (1998) and the a posteriori uncertainty is 0.08 compared to the a priori uncertainty of 0.4 . We note that when chondritic and cosmic compositions are used as initial guesses, the inversion returns slightly higher values of $\mu_{0}^{\prime}$ : $1.66 \pm 0.07$ compared to $1.59 \pm 0.08$ obtained for pyrolite. In order to investigate the trade-offs between $\mu_{0}$ and $\mu_{0}^{\prime}$, we perform an additional inversion using pyrolitic model and fixing the value of $\mu_{0}$ of perovskite to the experimental value of $173 \mathrm{GPa}$. The optimized value of $\mu_{0}^{\prime}$ increases from $1.59 \pm 0.08$ to $1.66 \pm 0.07$. The $\mathrm{Mg} / \mathrm{Si}$ ratio decreases from 1.26 to 1.21 making the vertical chemical gradient less pronounced. The resulting geotherm is hotter by $100 \mathrm{~K}$ at the depth of $2600 \mathrm{~km}$.

The optimized values of $\mu_{0}^{\prime}$ are in agreement with those obtained independently by the most recent Brillouin scattering results, $\mu_{0}^{\prime}=$ $1.7 \pm 0.2$ by Jackson et al. (2005) and $\mu_{0}^{\prime}=1.56 \pm 0.04$ by Murakami et al. (2007), by ab initio computations, $\mu_{0}^{\prime}=1.5$ in Kiefer et al. (2002), and is qualitatively in agreement with conclusions by Jackson (1998) and Deschamps \& Trampert (2004). On the contrary, they are not compatible with those by Li \& Zhang (2005) where $\mu_{0}^{\prime}=2.0 \pm 0.1$. The difference in conclusions between $\mathrm{Li}$ \& Zhang (2005) and our study, as well as those of Deschamps \& Trampert (2004) and Jackson (1998), are significant also in terms of inferred geotherm and lower-mantle composition. Aside the use of a different set of elastic properties, one possible reason for these discrepancies is that Li \& Zhang (2005) used an extrapolation technique based on different truncation order for different end-members. They introduced a second order pressure derivative of shear modulus $\mu_{0}^{\prime \prime}$ for magnesiowüstite whereas it was set to zero for perovskite phase. The second order pressure derivatives are very poorly constrained (if at all) and Li \& Zhang (2005) did not, however, evaluate the corresponding uncertainties. Also they did not quantify a possible bias introduced by their extrapolation technique that includes poorly constrained parameters. As a result, they obtained seismic velocities of magnesiowüstite that flatten out at mid-lower mantle depths. The effect of such flattening that may be related to an artefact of the extrapolation technique, is to increase the proportion of magnesiowüstite, that is, to increase $\mathrm{Mg} / \mathrm{Si}$ ratio, of a best-fitting compositional model.
Table 5. Variations of optimized temperature and $\mathrm{Mg} / \mathrm{Si}$ ratio at $2690 \mathrm{~km}$, and of $\mu_{0}$ and $\mu_{0}^{\prime}$ of $\mathrm{MgSiO}_{3}$-perovskite induced by the uncertainties on thermal parameters of Mie-Grüneisen EoS. Values of $\Theta_{D_{0}}, \gamma_{0}, q_{0}$ are taken from Table 2 .

\begin{tabular}{lcccc}
\hline & $T(\mathrm{~K})$ & $\mathrm{Mg} / \mathrm{Si}$ & $\mu_{0}(\mathrm{GPa})$ & $\mu_{0}^{\prime}$ \\
\hline$\theta_{D_{0}}, \gamma_{0}, q_{0}$ & $2942 \pm 300$ & $1.16 \pm 0.18$ & $177.9 \pm 2.9$ & $1.64 \pm 0.08$ \\
$\theta_{D_{0}} \pm 100 \mathrm{~K}$ & \pm 15 & \pm 0.01 & \pm 0.1 & $< \pm 0.01$ \\
$\gamma_{0} \pm 0.05$ & \pm 15 & \pm 0.01 & \pm 0.7 & $< \pm 0.01$ \\
$q_{0} \pm 0.5$ & \pm 80 & \pm 0.06 & \pm 0.1 & \pm 0.05 \\
\hline
\end{tabular}

In the previous calculations the uncertainties on the thermal parameters of Mie-Grüneisen EoS have not been taken into account. As $\mathrm{MgSiO}_{3}$-perovskite is the most abundant phase, we evaluate the effect on our inversion of varying its Debye temperature $\Theta_{D_{0}}$, Grüneisen parameter $\gamma_{0}$ and the volume derivative $q_{0}$. We adopt the uncertainties reported by Stixrude \& Lithgow-Bertelloni (2005). Table 5 shows the resulting variations of the temperature, composition as well as of the optimized value of the $\mathrm{MgSiO}_{3}$ shear modulus with the chondritic composition is used as initial guess. As a result, the a posteriori uncertainties of our results are increased by at most 30 per cent. Since the lower-mantle temperatures are greater than the Debye temperature, the results are only weakly sensitive to the choice of $\Theta_{D_{0}}$. Variations of $\gamma_{0}$ and $q_{0}$ are somewhat more important. Variations of $\gamma_{0}$ affect mostly the shear moduli whereas the uncertainties on $q_{0}$ impact the temperature estimates. We conclude that the results presented in this work are not affected, in their essence, by the uncertainties on the thermal corrections and that a low value of $\mu_{0}^{\prime}$, close to 1.6 , is always required in order to match the averaged seismological profiles.

\section{CONCLUDING REMARKS}

We have re-examined the classical problem of constraining the thermal structure and bulk composition from 1-D radial profiles of density and seismic velocities. A novel aspect in this paper is the application of a least-square criterion to solve generalized non-linear inversion, considering simultaneously all major chemical components, the evaluation of the complete covariance and resolution matrices, and the quantitative discussion of the uncertainties on the shear moduli. This approach allowed us to avoid built-in assumptions or biases associated with an arbitrary reduction of model parameters used in previous studies, and to identify the range of solutions that are consistent with seismic observables and the laboratory data base. We have showed that Bullen parameter allows us to discriminate between plausible thermal and compositional models of the lower mantle.

We have identified two significantly distinct families of bestfitting models and showed that the results are only marginally affected by the choice of the initial model. The first family is 
characterized by a geotherm with large temperature gradients $\left(d T / d z\right.$ varies between 0.5 and $\left.0.9 \mathrm{~K} \mathrm{~km}^{-1}\right)$. This solution is obtained in the case where the value of the pressure derivative of the shear modulus $\mu_{0}^{\prime}$ of $\mathrm{MgSiO}_{3}$-perovskite is set to 1.8 (Sinelnikov et al. 1998). The second family is obtained when the pressure derivative has a lower value, $\mu_{0}^{\prime}=1.6$, which is in an excellent agreement with the most recent experimental value obtained by Murakami et al. (2007). The resulting geotherm has smaller temperature gradients $\left(d T / d z\right.$ increases from $0.3 \mathrm{~K} \mathrm{~km}^{-1}$ in the upper part of the lower mantle to $0.5 \mathrm{~K} \mathrm{~km}^{-1}$ in the bottom part) and the temperature reaches $2800 \mathrm{~K}$ at the depth of $2700 \mathrm{~km}$.

Both families of best-fitting models are characterized by an average $\mathrm{Mg} / \mathrm{Si}$ ratio lower than 1.3 , that is, by a value that differs from the pyrolitic one and are similar in the upper part of the lower mantle (between 800 and $1700 \mathrm{~km}$ ). They are consistent with an constant $\mathrm{Mg} / \mathrm{Si}$ ratio of approximately 1.18 which corresponds to a mixture of 60 per cent of pyrolitic and 40 per cent of chondritic composition. The two families of models differ mostly in the bottom part of the lower mantle, below a depth of $1800 \mathrm{~km}$. On the one hand, assuming $\mu_{0}^{\prime}$ of 1.8 , the upper and bottom parts of the lower mantle seem to have a chemically and thermally distinct regime: an $\mathrm{Mg} / \mathrm{Si}$ ratio is close to 1.1 and temperature gradients are large, $d T / d z$ is about $0.8 \mathrm{~K} \mathrm{~km}^{-1}$, below the depth of $1800 \mathrm{~km}$. On the other hand, when a low value of $\mu_{0}^{\prime} \sim 1.6$, which is consistent with the most recent experimental results, is adopted, the bottom part of the lower mantle have $\mathrm{Mg} / \mathrm{Si}$ ratio close to 1.18 suggesting a more homogeneous mantle composition.

Constraints on the lower-mantle composition and temperature are very dependent on the measurements of shear moduli and particularly on their pressure dependence. In comparison, using only density and compressibility has significantly lower resolution and is strongly affected by trade-offs between temperature and composition (e.g. Mattern et al. 2005). The choice of the extrapolation technique may also a significantly affect the resulting thermal and compositional models. We show that the use of the Mie-Grüneisen EoS allows us to better control the thermal corrections.

The possibility to maintain compositional gradients without sharp interface in a convective mantle remains to be proved. However, if they exist, the seismological observations of a Bullen parameter $\eta$ of 1 do not imply that the thermal gradient of the mantle corresponds to the so-called adiabatic gradient, that is, $d T / d z$ may differ from $\alpha g T / C_{p}$ and $\eta \neq \eta_{H}$.

In order to further improve the resolution of lower-mantle composition and thermal structure additional independent observations are required. Recently, Khan et al. (2006) investigated the composition and thermal structure of the lower mantle using long-period electromagnetic sounding data. They obtained results that are in general agreement with our conclusions: the lower mantle is enriched in silica and temperature gradients are larger than those of Brown and Shankland's geotherm.

Alternatively, using 1-D $Q$ seismic profiles may help to make a further step. From seismic observations it follows that, on average, the $Q$ profile is rather constant in the depth range between 800 and $2700 \mathrm{~km}$ (see Romanowicz \& Durek 2000). Assuming that seismic attenuation is a thermally activated process, average $Q$ profiles can be constructed subject to various hypothesis (see e.g. Weertman 1970; Karato \& Karki 2001; Matas \& Bukowinski 2006). In order to keep the modelled values of quality factor $Q$ roughly constant with depth, additional constraints on the behaviour of the mantle geotherm may arise. Although the actual experimental uncertainties on the parameters required for such modelling are still large, future studies of seismic attenuation in the lower mantle is likely to help the understanding of lower-mantle structure.

\section{ACKNOWLEDGMENTS}

We thank to Don Anderson, Frédéric Deschamps and an anonymous reviewer for their comments as well as to Jun Korenaga for the editorial suggestions that helped to improve significantly the manuscript. This project was partially supported by the National Science Foundation (through grant EAR-00-03383 to JDB and EAR-00-0336951 to MSTB), and by a UIUC-CNRS collaborative grant. We also thank Jennifer Jackson for helpful discussions. This paper has also benefitted from fruitful discussions during the 3rd workshop on Mantle structure, composition and phase relations held in St. Malo, France, 2005.

\section{REFERENCES}

Aizawa, Y., Yoneda, A., Katsura, T., Ito, E., Saito, T. \& Suzuki, I., 2004. Temperature derivatives of elastic moduli of $\mathrm{MgSiO}_{3}$ perovskite, Geophys. Res. Lett., 31(L01602), doi:10.1029/2003GL018762.

Albarède, F., 2005. The Survival of Mantle Geochemical Heterogeneities, in Earth's Deep Mantle: Structure, Composition, and Evolution, pp. 2746, eds van der Hilst, R.D., Bass, J.D., Matas, J. \& Trampert, J., AGU, Washington DC.

Albarède, F. \& van der Hilst, R.D., 2002. Zoned mantle convection, Phil. Trans. R. Soc. Lond., 360, 2569-2592.

Allègre, C., Poirier, J.-P., Humler, E. \& Hofmann, A.W., 1995. The chemical composition of the Earth, Earth planet. Sci. Lett., 134, 515-526.

Anderson, D.L., 1983. Chemical composition of the Mantle, J. geophys. Res., 88(Suppl.), B41-B52.

Anderson, D.L., 1989. Theory of the Earth, Blackwell Scientific Publications, Oxford.

Anderson, D.L., 2005. Self-Gravity, self-consistency, and self-organization in geodynamics and geochemistry, in Earth's Deep Mantle: Structure, Composition, and Evolution, pp. 165-186, eds van der Hilst, R.D., Bass, J.D., Matas, J. \& Trampert, J., AGU, Washington DC.

Anderson, D.L. \& Bass, J.D., 1986. Transition region of the Earth's upper mantle, Nature, 320, 321-328.

Anderson, D.L. \& Hart, R.S., 1978. Q of the Earth, J. geophys. Res., 83, 5869-5882.

Badro, J., Fiquet, G., Guyot, F., Rueff, J.-P., Struzkin, V., Vankò, G. \& Monaco, G., 2003. Iron partitioning in Earth's mantle: toward a deep lower mantle discontinuity, Science, 300, 789-791.

Badro, J., Rueff, J., Vankò, G., Monaco, G, Fiquet, G. \& Guyot, F., 2004. Electronic transitions in Perovskite: possible nonconvecting layers in the lower mantle, Science, 305, 383-386.

Bonczar, L. \& Graham, E., 1982. The pressure and temperature dependence of the elastic properties of polycrystalline magnesiowüstite, J. geophys. Res., 87, 1061-1078.

Brown, J.M. \& Shankland, T.J., 1981. Thermodynamic parameters in the Earth as determined from seismic profiles, Geoph. J. R. astr. Soc., 66, 579-596.

Bullen, K.E., 1963. An index of degree of chemical inhomogeneity in the Earth, Geophys. J., 7, 584-592.

Bunge, P., Ricard, Y. \& Matas, J., 2001. Origin of lateral variation of seismic wave velocities and density in the deep mantle, Geophys. Res. Lett., 106(10), 879-882.

Cammarano, F., Goes, S., Deuss, A. \& Giardini, D., 2005. Is a pyrolitic adiabatic mantle compatible with seismic data?, Earth planet. Sci. Lett., 232, 227-243.

Christensen, U.R. \& Hofmann, A.W., 1994. Segregation of subducted oceanic crust in the convecting mantle, J. geophys. Res., 99, 1986719884. 
Cohen, R., 1987. Elasticity and equation of state of $\mathrm{MgSiO}_{3}$ perovskite, Geophys. Res. Lett., 14(10), 1053-1056.

Coltice, N. \& Ricard, Y., 1999. Geochemical observations and one-layer mantle convection, Earth planet. Sci. Lett., 174, 125-137.

da Silva, C., Wentzcowitch, R., Patel, A., Price, G. \& Karato, S., 2000. The composition and geotherm of the lower mantle: constraints from the elasticity of silicate perovskite, Phys. Earth planet. Inter, 118, 103-109.

Daniel, I., Bass, J., Fiquet, G., Cardon, H., Zhang, J. \& Hanfland M., 2004. Effect of aluminium on the compressibility of silicate perovskite, Geophys. Res. Lett., 31(15), doi:L15608 10.1029/2004GL020213.

Davaille, A., 1999. A simultaneous generation of hotpots and superswells by convection in a heterogeneous planetary mantle, Nature, 402, 756-760.

Davies, G., 1974. Effective elastic moduli under hydrostatic stress. 1. Quasiharmonic theory, J. Phys. Chem. Solids, 35(11), 1513-1520.

Deschamps, F. \& Trampert, J., 2004. Towards a lower mantle reference temperature and composition, Earth planet. Sci. Lett., 122, 161-175.

Duffy, T. \& Anderson, D.L., 1989. Seismic velocities in the mantle minerals and the mineralogy of the upper mantle, J. geophys. Res., 94(B2), 18951912.

Dziewonski, A.M. \& Anderson, D.L., 1981. Preliminary reference Earth model, Phys. Earth planet. Inter, 25, 297-356.

Fiquet, G., Andrault, D., Dewaele, A., Charpin, T., Kunz, M. \& Haüserman, D., 1998. P-V-T equation of state of $\mathrm{MgSiO}_{3}$ perovskite, Phys. Earth planet. Inter, 105, 21-31.

Garnero, E., 2004. A new paradigm for earth's core-mantle boundary, Science, 304, 834-836.

Green, D.H. \& Ringwood, A.E., 1963. Mineral assemblages in a model mantle composition, J. geophys. Res., 68, 937-945.

Hama, J. \& Suito, K., 1998. High-temperature equation of state of CaSiO 3 perovskite and its implications for the lower mantle, Phys. Earth planet. Inter., 105, 33-46.

Hama, J. \& Suito, K., 2001. Thermoelastic models of minerals and the composition of the Earth's lower mantle, Phys. Earth planet. Inter, 125, $147-$ 166.

Hart, S.R. \& Zindler, A., 1986. In search of a bulk-Earth composition, Chem. Geol., 57, 247-267.

Hirose, K., 2002. Phase transitions in pyrolitic mantle around 670-km depth: implications for upwelling of plumes from the lower mantle, J. geophys. Res., 107(B2), doi:10.1029/2001B000597.

Hofmann, A.W., 1997. Mantle geochemistry: the message from oceanic volcanism, Nature, 385, 219-229.

Hofmeister, A.M., 2006. Is low-spin $\mathrm{Fe}^{+2}$ present in the Earth's mantle?, Earth planet Sci. Lett., 243, 44-52.

Jackson, I., 1998. Elasticity, composition and the temperature of the Earth's lower mantle: a reappraisal, Geophys. J. Int., 134, 291-311.

Jackson, I. \& Niesler, H., 1982. The elasticity of periclase to $3 \mathrm{GPa}$ and some geophysical implications, in High Pressure in Geophysics, pp. 93-113, eds Akimoto, S. \& Manghnani, M.H., Center for Academic Publications, Tokyo.

Jackson, I. \& Ridgen, S.M., 1998. Composition and temperature of the Earth's mantle: seismological models interpreted through experimental studies of Earth materials, in The Earth's Mantle: Composition, Structure and Evolution, pp. 405-460, ed. Jackson, I., Cambridge University Press, New York.

Jackson, I., Khanna, S., Revcolevschi, A. \& Berthon, J., 1990. Elasticty, shear mode-softening and high-pressure polymorphism of wüstite $\left(\mathrm{Fe}_{1-x} \mathrm{O}, J\right.$. geophys. Res., 95(B13), 21 671-21 685.

Jackson, I., Liebermann, R.C. \& Ringwood, A., 1978. The elastic properties of $\left(\mathrm{Mg}_{x}, \mathrm{Fe}_{1-x}\right) \mathrm{O}$ solid solutions, Phys. Chem. Min., 3, 11-31.

Jackson, J.M., Bass, J.D. \& Zhang, J., 2004. Sound velocities of aluminous $\mathrm{MgSiO}_{3}$ perovskite: implications for the Earth's lower mantle, Geophys. Res. Lett., 31(L10614), doi:10.1029/2004GL019918.

Jackson, J.M., Zhang, J., Shu, J., Sinogeikin, S.V. \& Bass, J.D., 2005. Highpressure sound velocities and elasticity of aluminous $\mathrm{MgSiO} 3$ perovskite to $45 \mathrm{GPa}$ : implications for lateral heterogeneity in Earth lower mantle, Geophys. Res. Lett., 32(L21305), doi:10.1029/2005GL023522.

Jacobsen, S., Reichman, H.J., Spetzler, H., Mackwell, S., Smyth, J., Angel, R. \& McCammon, C., 2002. Structure and elasticity of single-crystal (Mg,
$\mathrm{Fe}) \mathrm{O}$ and a new method of generating shear waves for gigahertz ultrasonic interferometry, J. geophys. Res., 107(B2), doi:10.1029/2001B000490.

Jarosewich, E., 1990. Chemical analyses of meteorites: a compilation of stony and iron meteorite analyses, Meteoritics, 25, 323-337.

Javoy, M., 1995. The integral enstatite chondrite model of the Earth, Geophys. Res. Lett., 22, 2219-2222.

Kantor, A.P., Jacobsen, S.D., Kantor, Y.K., Dubrovinsky, L.S., McCammon, C.A., Reichmann, H.J. \& Goncharenko, I.N., 2004. Pressure-induced magnetization in $\mathrm{FeO}$ : evidence from elasticity and Mssbauer spectroscopy, Phys. Rev. Lett., 93, 215502.

Karato, S-I. \& Karki, B.B., 2001. Origin of lateral variation of seismic wave velocities and density in the deep mantle, J. geophys. Res., 28(10), 21771 21783.

Karato, S.-I. \& Spetzler, H.A., 1990. Deffect microdynamics in minerals and solid-state mechanisms of seismic wave attenuation and velocity dispersion in the mantle, Rev. Geophys., 28, 399-421.

Karki, B. \& Crain, J., 1998. First-principles determination of elastic properties of $\mathrm{CaSiO}_{3}$ perovskite at lower mantle pressures, Geophys. Res. Lett., 25(14), 2741-2744.

Karki, B., Wentzcowitch, R., de Gironcoli, S. \& Baroni, S.L., 1999. Firstprinciples determination of elastic anisotropy and wave velocities of $\mathrm{MgO}$ at lower mantle conditions, Science, 286, 1705-1707.

Katsura, T. et al., 2003. Post-spinel transition in $\mathrm{Mg} 2 \mathrm{SiO} 4$ determined by high P-T in situ X-ray diffraction, Phys. Earth planet. Inter, 136, 11-24.

Kellogg, L.H., Hager, B.H. \& van der Hilst, R.D., 1999. Compositional stratification in the deep mantle, Science, 283, 1881-1884.

Kennett, B. \& Engdahl, E.R., 1991. Traveltimes for global earthquake locations and phase identifications, Geophys. J. Int., 105, 429-465.

Kennett, B., Engdahl, E.R. \& Buland., R., 1995. Constraints on seismic velocities in the Earth from travel times, Geophys. J. Int., 122, 108-124.

Kennett, B.L.N. \& Gorbatov, A., 2004. Seismic heterogeneity in the mantlestrong shear wave signature of slabs from joint tomography, Phys. Earth planet. Inter, 146, 87-100.

Kennett, B.L.N., Widiyantoro, S. \& van der Hilst, R.D., 2001. Joint seismic tomography for bulk sound and shear wave speed in the Earth's mantle, $J$. geophys. Res., 103(B6), 12 469-12 493.

Khan, A., Connolly, J.A.D. \& Olsen, N., 2006. Constraining the composition and thermal state of the mantle beneath Europe from inversion of longperiod electromagnetic sounding data, J. geophys. Res., 111(B10102), doi:10.1029/2006JB004270.

Kiefer, B., Stixrude, L. \& Wentzcowitch, R., 2002. Elasticity of (Mg, $\mathrm{Fe}) \mathrm{SiO}_{3}$-perovskite at high pressures, Geophys. Res. Lett., 29(11), doi:10.1029/2002GL014683.

Kung, J., Li, B., Weidner, D. \& Liebermann, R.C., 2002. Elasticity of $\left(\mathrm{Mg}_{0.83}\right.$, $\left.\mathrm{Fe}_{0.17}\right) \mathrm{O}$ ferropericlase at high pressure: ultrasonic measurements in conjunction with X-radiation techniques, Earth planet. Sci. Lett., 203, $557-$ 566.

Lee, K.K.M., O'Neill, B., Panero, W.D., Shim, S.-H., Benedetti, L.R. \& Jeanloz, R., 2004. Equations of state of the high-pressure phases of a natural peridotite and implications for the Earth lower mantle, Earth planet. Sci. Lett., 223, 381-393.

Li, B. \& Zhang, J., 2005. Pressure and temperature dependence of elastic wave velocity of $\mathrm{MgSiO}_{3}$ perovskite and the compsoition of the lower mantle, Phys. Earth planet. Inter, 151, 143-154.

Li, J. et al., 2004. Electronic spin state of iron in lower mantle perovskite, Proc. Natl. Acad. Sci. USA, 101(39), 14 027-14030.

Li, B., Kung, J., Uchida, T. \& Wang, Y., 2005. Pressure calibration to $20 \mathrm{GPa}$ by simultaneous use of ultrasonic and X-ray techniques, J. Appl. Phys., 98, 0135231.

Lyubetskaya, T. \& Korenaga, J., 2007. Chemical composition of Earth's primitive mantle and its variance, 1. Method and results, J. geophys. Res., 112(B3), BO3211, doi:10.1029/2005JB4223, 2007.

Masters, G. \& Gubbins, D., 2003. On the resolution of density within the Earth, Phys. Earth planet. Inter, 140, 159-167.

Masters, G., Laske, G., Bolton, H. \& Dziewonski, A., 2000. The relative behavior of shear velocity, bulk sound speed, and compressional velocity in the mantle: implications for chemical and thermal structure, in Earth's Deep Interior: Mineral Physics and Tomography from Atomic to the Global 
Scale, pp. 63-87, eds Karato, S., Forte, A.M., Liebermann, R.C., Masters, G. \& Stixrude, L., AGU, Washington DC.

Matas, J. \& Bukowinski, M.S.T., 2006. On the anelastic contribution to the temperature dependence of lower mantle seismic velocities, EOS, Trans. Am. geophys. Un., 87(52), MR23A-08.

Matsui, M., 2000. Molecular dynamics simulation of $\mathrm{MgSiO}_{3}$ perovskite and the $660-\mathrm{km}$ discontinuity, Phys. Earth planet. Inter., 121, 7784.

Mattern, E., Matas, J., Ricard, Y. \& Bass, J.D., 2005. Lower mantle composition and temperature from mineral physics and thermodynamic modelling, Geophys. J. Int., 160, 973-990.

McDonough, W.F. \& Sun, S.-S., 1995. The composition of the Earth, Chem. Geol., 120, 223-253.

Minster, J.B. \& Anderson, D.L., 1981. A model of dislocation controlled rheology for the mantle, Phil. Trans. R. Soc. Lond., 299(A), 319-356.

Morelli, A. \& Dziewonski, A., 1993. Body wave traveltimes and a spherically symmetric P- and S-wave velocity model, Geophys. J. Int., 112, 178-194.

Morgan, J.W. \& Anders, E., 1980. Chemical composition of Earth, Venus and Mercury, Proc. Natl. Acad. Sci., 77, 6973-6977.

Murakami, M., Hirose, K., Kawamura, K., Sata, N. \& Ohishi, Y., 2004. Post-perovskite phase transition in $\mathrm{MgSiO}_{3}$, Science, 304, 855-858.

Murakami, M., Sinogeikin, S.V., Hellwig, H. \& Bass, J.D., 2007. Sound velocities of $\mathrm{MgSiO}_{3}$ perovskite to megabar pressure and the mineralogy of Earth's lower mantle, Earth planet. Sci. Lett., in press, doi:10.1016/j.opsl.2007.01.011

Newsom, H., 1995. Composition of the solar system, planets, meteorites, and major terrestrial reservoirs, in Global Earth Physics: A Handbook of Physical Constants, pp. 159-188, AGU Reference Shelf 1.

Oganov, A., Brodholt, J. \& Price, D., 2001. Ab initio elasticity and thermal equation of state of $\mathrm{MgSiO}_{3}$ perovskite, Earth planet. Sci. Lett., 184, 555-560.

Ricard, Y. \& Coltice, C., 2004. Geophysical and geochemical models of mantle convection: successes and future challenges, in State of the Planet: Frontiers and Challenges in Geophysics, pp. 59-68, eds Stephen, R., Sparks, J. \& Hawkesworth, C.J., AGU Geophysical monograph.

Ricard, Y., Fleitout, L. \& Froidevaux, C., 1984. Geoid hights and lithospheric stresses for a dynamic Earth, Ann. Geophysica, 2, 267-286.

Richards, M.A. \& Hager, B., 1984. Geoid anomalies in a dynamic Earth, J. geophys. Res., 89, 5987-6002.

Ringwood, A.E., 1991. Phase transformations and their bearing on the constitution and dynamics of the mantle, Geochim. Cosmochim. Acta, 55, 2083-2110.

Ringwood, A.E. \& Kesson, S., 1977. Siderophile and volatile elements in Moon, Earth and chondrites, Moon, 16, 425.

Robertson, G.S. \& Woodhouse, J.H., 1996. Constraints on lower mantle physical properties from seismology and mineral physics, Earth planet. Sci. Lett., 143, 197-205.

Romanowicz, B. \& Durek, J.J., 2000. Seismological constraints on attenuation in the Earth: a review, in Earth's Deep Interior: Mineral Physics and Tomography From Atomic to the Global Scale, pp. 161-179, eds Karato, S., Forte, A., Liebermann, R., Masters, G. \& Stixrude, L., AGU, Washington DC.

Saltzer, R.L., van der Hilst, R.D. \& Karáson, H., 2001. Comparing P and S wave heterogeneity in the mantle, Geophys. Res. Lett., 28(7), 13351338.

Samuel, H., Farnetani, C.G. \& Andrault, D., 2005. heterogeneous lowermost mantle: compositional constraints and seismological observables, in Earth's Deep Mantle: Structure, Composition, and Evolution, pp. 103118, eds van der Hilst, R.D., Bass, J.D., Matas, J. \& Trampert, J., AGU, Washington DC.

Shim, S.H., Duffy, T. \& Shen, G., 2000. The equation of state of $\mathrm{CaSiO}_{3}$ perovskite to $108 \mathrm{GPa}$ at $300 \mathrm{~K}$, Phys. Earth planet. Inter., 120, 327-338.

Sinelnikov, Y., Chen, G., Neiville, Vaughan, M. \& Liebermann, R.C., 1998. Ultrasonic shear wave velocities of $\mathrm{MgSiO}_{3}$ perovskite at $8 \mathrm{GPa}$ and 800 $\mathrm{K}$ and lower mantle composition, Science, 281, 677-679.

Sinogeikin, S. \& Bass, J.D., 2000. Single-crystal elasticty of pyrope and $\mathrm{MgO}$ to $20 \mathrm{GPa}$ by Brillouin scattering in the diamond cell, Phys. Earth planet. Inter., 126, 43-62.
Sinogeikin, S., Zhang, J. \& Bass, J.D., 2004. Elasticity of $\mathrm{MgSiO}_{3}$ polycrystalline perovskite by Brillouin spectroscopy, Geophys. Res. Lett., 31(L066220), doi:10.1029/2004GL019559.

Speziale, S., Milner, A., Lee, V.E., Clark, S.M., Pasternak, M.P. \& Jeanloz, R., 2005. Iron spin transition in Earth mantle, P. Natl. Acad. Sci. USA, 102(50), 17918-17922.

Stacey, F.D. \& Davis, P.M., 2004. High pressure equations of state with applications to the lower mantle and core, Phys. Earth planet. Inter., 142, 137-184.

Stixrude, L. \& Bukowinski, M.S.T., 1990. Fundamental thermodynamic relations and silicate melting with implications for the constitution of the of $\mathrm{D}^{\prime \prime}$, J. geophys. Res., 95, 19311-19325.

Stixrude, L. \& Lithgow-Bertelloni, C., 2005. Thermodynamics of mantle minerals: 1. Physical properties, J. geophys. Res., 162, 610-632, doi:10.1111/j.1365-246X.2005.02642.x.

Su, W.-J. \& Dziewonski, A.M., 1997. Simoultaneous inversions for 3-D variations in shear and bulk velocity in the mantle, Phys. Earth planet. Inter, 100, 135-156.

Sumino, Y., Kumazawa, M., Nishizawa, O. \& Pluschkell, W., 1980. The elastic constants of single-crystal $\mathrm{Fe}_{1-x} \mathrm{O}, \mathrm{MnO}, \mathrm{CoO}$ and the elasticity of stoichiometric magnesiowüstite, J. Phys. Earth, 28, 475-495.

Tackley, P., Xie, S., Nakagawa, T. \& Hernlund, J.W., 2005. Numerical and laboratory studies of mantle convection: philosophy, accomplishments, and thermochemical structure, in Earth's Deep Mantle: Structure, Composition, and Evolution, pp. 85-102, eds van der Hilst, R.D., Bass, J.D., Matas, J. \& Trampert, J., AGU, Washington DC.

Tarantola, A., 1987. Inverse problem theory: Methods for Data Fitting and Model Parameter Estimation. Elsevier, New York.

Tarantola, A. \& Valette, B., 1982. Generalized non-linear inverse problems solved using the least square criterion, Rev. Geophys. Space Phys., 20(2), 219-232.

Trampert, J. \& van der Hilst, R.D., 2005. Towards a quantitative interpretation of global seismic tomography, in Earth's Deep Mantle: Structure, Composition, and Evolution, pp. 47-64, eds van der Hilst, R.D., Bass, J.D., Matas, J. \& Trampert, J., AGU, Washington DC.

van der Hilst, R.D. \& Karason, H., 1999. Compositional heterogeneity in the bottom $1000 \mathrm{~km}$ of the Earth's mantle: towards a hybrid convectional model, Science, 283, 1885-1888.

Watt, J., Davies, G. \& O'Connell, J., 1976. The elastic properties of composite minerals, Rev. Geophys. Space Phys., 14, 541-563.

Weertman, J., 1970. The creep strength of the Earth's mantle, Rev. Geophys. Space Phys., 8, 145-168.

Wentzcovitch, R., Karki, B., Cococcioni, M. \& de Gironcoli, S., 2004. Thermoelastic properties of $\mathrm{MgSiO}_{3}$-perovskite: insights on the nature of the Earth's lower mantle, Phys. Rev. Lett., 92, 018501.

Williams, Q. \& Knittle, E., 2005. The uncertain major element bulk composition of earths mantle, in Earth's Deep Mantle: Structure, Composition, and Evolution, pp. 189-202, eds van der Hilst, R.D., Bass, J.D., Matas, J. \& Trampert, J., AGU, Washington DC.

Wood, B.J. \& Rubie, D.C., 1996. the effect of alumina on phase transformations at the 660-kilometer discontinuity from Fe-Mg partitioning experiments, Science, 263, 1522-1524.

Yeganeh-Haeri, A., Weidner, D. \& Ito, E., 1989. Elasticity of $\mathrm{MgSiO}_{3}$ in the perovskite structure, Science, 243, 787-789.

\section{APPENDIX A: ISOTHERMAL COMPRESSION}

\section{A1 Birch-Murnaghan equation of state}

The third-order Birch-Murnaghan equation of state is based on finite strain theory. It is a widely used equation of state in Earth Sciences. At a given reference temperature $T_{0}$, it relates pressure $P$ and molar volume $V\left(P, T_{0}\right)$ as follows:

$\frac{P}{K_{T}\left(P_{0}, T_{0}\right)}=\frac{3}{2} x^{5 / 3}\left[x^{2 / 3}-1\right] \times\left\{1-\frac{3}{4}\left(4-K_{0}^{\prime}\right)\left[x^{2 / 3}-1\right]\right\}$, 


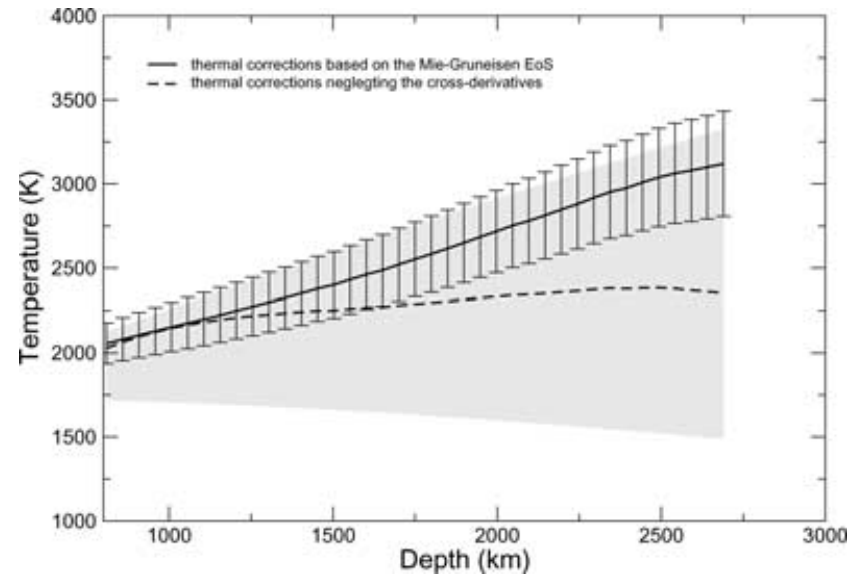

Figure A1. The influence of the extrapolation method of bulk modulus on the best-fitting geotherms when density $\rho$ and bulk sound velocity $V_{\phi}$ are being matched by the inversion. The thermal corrections obtained from a Mie-Grüneisen EoS (solid line) yield geotherms with larger temperature gradient compared to high-temperature finite-strain thermal corrections when neglecting the cross-derivatives of the incompressibility (dashed line). The temperature difference exceeds the a posteriori uncertainties below the depth $1500 \mathrm{~km}$ and can be as large as $700 \mathrm{~K}$ at the depth of $2700 \mathrm{~K}$ in the case of the chondritic composition. The a priori geotherm by Brown \& Shankland (1981) and a priori Gaussian bounds changing linearly from $\pm 200 \mathrm{~K}$ at 800 $\mathrm{km}$ to $\pm 1000 \mathrm{~K}$ at $2700 \mathrm{~km}$ are depicted by the grey shading.

where $x=V\left(P_{0}, T_{0}\right) / V\left(P, T_{0}\right)$ and $V\left(P_{0}, T_{0}\right)$ is the molar volume at room pressure, $P_{0}=10^{5} \mathrm{~Pa}$, and temperature $T_{0}=298.15 \mathrm{~K} . K_{T}$ and $K_{0}^{\prime}$, are the isothermal bulk modulus and its pressure derivative at room pressure. $K_{T}\left(P, T_{0}\right)$ can be obtained by differentiating eq. (A1) with respect to pressure:

$\frac{K_{T}\left(P, T_{0}\right)}{P}=\frac{\frac{5}{3} A x^{5 / 3}-\frac{7}{3} B x^{7 / 3}+3 C x^{3}}{A x^{5 / 3}-B x^{7 / 3}+C x^{3}}$

with the following coefficients $A=-2\left(K_{0}^{\prime}-4\right)+8 / 3, B=$ $-4\left(K_{0}^{\prime}-4\right)+8 / 3$, and $C=B-A$. Details can be found in, for example, Stacey \& Davis (2004).

\section{A2 Effect of pressure on shear properties}

For the shear modulus we use an analytical form obtained by Davies (1974) in analogy with the finite-strain EoS to compute the shear modulus $\mu$ :

$\frac{\mu\left(P, T_{0}\right)}{\mu\left(P_{0}, T_{0}\right)}=x^{5 / 3}\left\{1-\frac{1}{2}\left(x^{2 / 3}-1\right)\left[5-3 \mu_{0}^{\prime} \frac{K_{T}\left(P_{0}, T_{0}\right)}{\mu\left(P_{0}, T_{0}\right)}\right]\right\}$

where $\mu_{0}^{\prime}=\left(\partial \mu_{0} / \partial P\right)_{T}$. The numerical values for the lower-mantle minerals used in this study are reported in Table 1.

\section{APPENDIX B: THERMAL CORRECTIONS}

\section{B1 Debye model or Mie-Grüneisen thermal EoS}

A detailed physical description of the Debye model can be found in most of classical thermodynamics books. Here we only briefly summarize the basic concepts and expressions. The Helmholtz free energy $F(V, T)$ can be written as

$F(V, T)=\frac{9 n R T}{V} \frac{1}{x^{3}} \int_{0}^{x} \xi^{2} \ln \left(1-e^{-\xi}\right) d \xi$,

where $x=\Theta_{D} / T$, with $\Theta_{D}$ being the Debye temperature, $R$ the universal gas constant, $n$ the number of atoms per molar formula (i.e. $n=5$ and 2 for perovskite and magnesiowustite, respectively). Using various thermodynamic relations such as

$P_{t h}(V, T)=-\left[\frac{\partial F(V, T)}{\partial V}\right]_{T}, \quad K_{T}(V, T)=-V\left[\frac{\partial P(V, T)}{\partial V}\right]_{T}$,

and defining the Debye function as

$D(x)=\frac{3}{x^{3}} \int_{0}^{x} \frac{\xi^{3}}{e^{\xi}-1} d \xi$

the thermal contribution to the elastic properties can be expressed in the following way

$P_{t h}(V, T)=\frac{3 n \gamma R T}{V} D(x)$

and

$K_{T t h}(V, T)=\frac{3 n R T}{V} \gamma\left[\left(1-q_{0}-3 \gamma\right) D(x)+3 \gamma \frac{x}{e^{x}-1}\right]$.

Since we adopt the quasi-harmonic approximation, the Debey temperature $\Theta_{D}$, and the Grüneisen parameter $\gamma$ are functions of volume only:

$\Theta_{D}(V)=\Theta_{D_{0}}\left(V_{0}\right) \exp \left(\frac{\gamma_{0}-\gamma}{q_{0}}\right), \quad \gamma(V)=\gamma_{0}\left(V_{0}\right)\left(\frac{V}{V_{0}}\right)^{q_{0}}$.

The values of the three parameters $\Theta_{D_{0}}, \gamma_{0}$, and $q_{0}$ for $\mathrm{MgSiO}_{3}$ and $\mathrm{MgO}$ are adopted from the study by Stixrude \& Lithgow-Bertelloni (2005) (see Table 2). The total pressure and bulk modulus as a function of temperature $T$ and volume $V$ are computed by adding both the reference isothermal properties obtained from an isothermal equation of state (see Appendix A) and the thermal corrections as follows:

$P(V, T)=P_{\text {ref }}\left(V, T_{0}\right)+P_{t h}(V, T)-P_{t h}\left(V, T_{0}\right)$

and

$K_{T}(V, T)=K_{T_{\text {ref }}}\left(V, T_{0}\right)+K_{T t h}(V, T)-K_{T t h}\left(V, T_{0}\right)$.

The coefficient of thermal expansion is computed using the following relation

$\alpha(V, T)=\frac{1}{K_{T}}\left[\frac{\partial P(V, T)}{\partial T}\right]_{V}$.

The thermal correction for the shear properties are not straight forward. We adopt an expression equivalent to the thermal corrections developed by Hama \& Suito (1998):

$\mu_{t h}(V, T)=\frac{3}{5}\left[K_{T_{t h}}(V, T)-2 \frac{3 n R T}{V} \gamma D(x)\right]$.

The total shear properties are also obtained by adding both the static shear properties and the thermal corrections as

$\mu(V, T)=\mu_{\text {ref }}\left(V, T_{0}\right)+\mu_{t h}(V, T)-\mu_{t h}\left(V, T_{0}\right)$. 


\section{B2 Experimental high-temperature finite-strain}

An alternative way for computing the thermal corrections is possible with using temperature derivatives of volume and of elastic parameters such as thermal expansion $\alpha\left(P_{0}, T\right)$ and $\left(\partial K_{0, T} / \partial T\right)_{P}$ extracted from $P-V-T$ measurements (see Table 2). Assuming the cross-derivative $\partial^{2} K_{T} / \partial P \partial T=0$, that is, that the same $K_{0}^{\prime}$ can be used at all $T$ (which can introduce errors), it is possible to compute both the molar volume and the bulk modulus at arbitrary temperature $T$ by

$V\left(P_{0}, T\right)=V\left(P_{0}, T_{0}\right) \exp \left[\int_{T_{0}}^{T} \alpha\left(P_{0}, T^{\prime}\right) \mathrm{d} T^{\prime}\right]$

$K_{T}\left(P_{0}, T\right)=K_{T}\left(P_{0}, T_{0}\right)+\left(\frac{\partial K_{0, T}}{\partial T}\right)_{P}\left(T-T_{0}\right)$.

High-temperature molar volume $V\left(P_{0}, T\right)$ and room pressure incompressibility $K_{T}\left(P_{0}, T\right)$ are then used in a isothermal finite-strain equation instead of reference temperature values in order to account for the compression from $P_{0}$ to $P$. In Table 2 , a linear dependence of $\alpha$ with temperature is adopted and, thus, $\alpha(T)=\alpha_{0}+\alpha_{1} T$. We show the comparison of the two approaches for thermal corrections in Appendix C.

\section{APPENDIX C: COMPARISON BETWEEN TWO DIFFERENT EXTRAPOLATION TECHN I QUES}

The extrapolation of the elastic properties to lower mantle conditions is not straightforward and can be performed by using different methods. Above we have briefly discussed two of them: the Debye thermal corrections and the isothermal high-temperature finite-strain EoS. We note that the latter differs for the adiabatic high-temperature finite-strain EoS used for example by Jackson (1998) and Deschamps \& Trampert (2004). The isothermal hightemperature finite-strain EoS is based on experimental observations of temperature derivatives of the volume and elastic parameters (e.g. $\alpha$ and $\left.\left(\partial K_{T} / \partial T\right)_{P}\right)$ obtained from a fit of high pressure and high temperature $P-V-T$ measurements. Due to experimental difficulties of simultaneous high-pressure and high-temperature observations, the temperature derivatives at high pressure are the least constrained parameters. As pointed out by Jackson (1998) and Deschamps \& Trampert (2004), accurate values of the cross-derivatives of the incompressibility, $\partial^{2} K_{T} / \partial P \partial T$, should be used when extrapolating the elastic moduli to lower-mantle $P-T$ conditions.

In Fig. A1, we show a comparison of results obtained by these two extrapolation techniques when the density $\rho$ and bulk sound velocity $V_{\phi}$ are considered as observations. In this computation, we use the temperature derivatives $\left(\partial K_{0, T} / \partial T\right)_{P}$ and coefficient of thermal expansion $\alpha(T)$ as reported by Mattern et al. (2005). Using the Mie-Grüneisen EoS that provides a self-consistent thermodynamic approach, the geotherms have a super-adiabatic gradient (the Bullen parameter $\eta$ is lower than 1) while they are subadiabatic (see also Mattern et al. 2005) when the cross-derivatives are neglected in the high temperature finite strain EoS. The temperature difference exceeds the a posteriori uncertainties below the depth $1500 \mathrm{~km}$ and can be as large as $700 \mathrm{~K}$ at the depth of $2700 \mathrm{~K}$. We verified that the two methods predict similar densities, but their incompressibilities differ by 3 per cent (at most) at $2700 \mathrm{~km}$ depth.
This difference is responsible for the superadiabatic temperature gradients and hotter geotherms observed in Fig. A1. We have also computed the evolution of the temperature derivative $\left(\partial K_{S} / \partial T\right)_{P}$ with pressure. When the Mie-Grüneisen approach is used, a physically sounded behaviour of $\left(\partial K_{S} / \partial T\right)_{P}$ is observed: it decreases with depth as the effect of temperature is lowered by the increasing pressure. On the contrary, $\left(\partial K_{S} / \partial T\right)_{P}$ increases with depth when the cross-derivatives are neglected. Such behaviour reveals possible artefacts that may be associated with this extrapolation technique. We note that the slope of $\left(\partial K_{S} / \partial T\right)_{P}$ is related to the third volume derivatives which enhances any potential inconsistency of the applied extrapolation technique. In this study, we therefore, favour the use the Mie-Grüneisen approach.

\section{APPENDIX D: BULK PROPERTIES OF AN ASSEMBLAGE (AVERAGING SCHE M ES )}

Within the two solid solutions considered in this study, perovskite and magnesiowüstite phase, $(\mathrm{CaPv}$ is considered as a single-species phase), the effect of the end-members on elastic properties of the phase is linearly proportional to the molar proportion each endmember. The corresponding coefficients for $V_{0}, K_{0}, K_{0, T}^{\prime}, \mu_{0}$ and $\mu_{0}^{\prime}$ are obtained directly from the Table 1 .

The bulk properties of the lower mantle can be computed from the molar abundances $n_{i}$ of each mineralogical phase $i$, that is, of $\mathrm{Pv}, \mathrm{Mw}$ and $\mathrm{CaPv}$, and their elastic properties. The volume of an assemblage is obtained from:

$V=\sum_{i} n_{i} V_{i}$

where $V_{i}$ is the partial molar volume of the phase $i$. The density $\rho$ of the assemblage is given by:

$\rho=\frac{1}{V} \sum_{i} n_{i} M_{i}$

where $M_{i}$ is the molar weight. The adiabatic incompressibility $K_{S}$ and bulk shear modulus are less straightforward to compute since there exists different averaging techniques depending on the macroscopic structure (texture) of composite material. Here we only give definitions for the two most important averages: Voigt and Reuss averages. Defining a volumetric fraction $v_{i}$ as

$v_{i}=\frac{x_{i} V_{i}}{V}$

the Voigt average of incompressibility and of bulk shear modulus is given by

$X^{V}=\sum_{i} v_{i} X_{i}$

and the Reuss average by

$X^{R}=\left(\sum_{i} \frac{v_{i}}{X_{i}}\right)^{-1}$,

where $X_{i}$ stands for $K_{S_{i}}$ and $\mu_{i}$. In both cases, Reuss and Voigt model, $K_{S_{i}}$ of each phase is computed as follows

$K_{S_{i}}=K_{T_{i}}\left(1+\alpha_{i} \gamma_{i} T\right)$. 
Watt et al. (1976) warned that neither Voigt nor Reuss average is likely to correspond to reality. They preferred the arithmetic average of the two previous averages, so-called Reuss-Voigt-Hill average

$X^{\mathrm{RVH}}=\frac{X^{V}+X^{R}}{2}$

or the more sophisticated Hashin and Shtrikman's averaging scheme. Since the three lower-mantle mineralogical phases have elastic prop- erties that are not too different, and the two previous schemes do not differ significantly in their results, we adopt the simpler ReussVoigt-Hill average. Finally, the different velocities $V_{p, s, \phi}$ discussed in this study are computed as

$$
V_{p}=\sqrt{\frac{K_{S}+4 / 3 \mu}{\rho}}, \quad V_{s}=\sqrt{\frac{\mu}{\rho}}, \quad V_{\phi}=\sqrt{\frac{K_{S}}{\rho}} .
$$

